\title{
PARA UNA SOCIOLOGÍA DE LA FOTOGRAFÍA
}

\author{
Jesús M. de Miguel
}

Universidad de Barcelona

E-mail: demiguel@eco.ub.es

\section{Omar G. Ponce de León}

Universidad Autónoma del Estado de Morelos, Cuernavaca, México

E-mail: omar@dunsun.dti.uaem.mx

\begin{abstract}
RESUMEN
La Fotografía se inventa en 1839, la misma fecha en que Auguste Comte empieza a escribir sobre la nueva ciencia de la Sociología. El famoso Discours sur l'esprit positif se publica un lustro después. Es interesante recordar que ese "discurso» es en realidad un prólogo, largo (de unas 140 páginas), a su Tratado filosófico de astronomía popular. La visión del mundo a través del anteojo o del teleobjetivo es, pues, iniciada por el nuevo espíritu positivo de la Sociología. Fotografía y Sociología son dos disciplinas hermanas, francesas por nacimiento, relacionadas desde su inicio. Ambas nacen en Europa, se exportan a América, y se reimportan a finales del siglo XX desde Estados Unidos a Europa. Vienen entonces con ropajes y temas nuevos pero conservan un sabor antiguo. En esta migración de retorno, o en su naufragio, muchos europeos/as perdieron el interés por las ciencias sociales lo mismo que por la fotografía. En los años del presente fin du siècle se observa un renovado interés por la fotografía como instrumento de análisis social. La fotografía fija es una mezcla de arte y técnica (mecánica y química) que consiste en congelar un instante del tiempo. En este sentido, el análisis del «momento decisivo» se puede convertir en un instrumento excelente de análisis de la realidad social. A menudo se transforma también en una construcción de esa realidad social, distinta pero comparable a la que es capaz de producir un texto escrito. Idealmente, la combinación de texto escrito e imagen proyectada es el objetivo fundamental de la sociología en el siglo XXI.
\end{abstract}

La Sociología de la Fotografía es un campo todavía por desarrollar en la sociología española y latinoamericana. Las siguientes páginas se dedican a defi-

\section{Reis}


nir la agenda de este nuevo interés y campo intelectual ${ }^{1}$. La fotografía ${ }^{2}$ permite preservar un fragmento del pasado, una imagen de algo que no volverá a repetirse, y que incluso puede haber desaparecido. Las personas en una foto quizá están muertas, los edificios son otros. Es posible que las personas vivan, pero no tienen ya la misma edad. Indefectiblemente toda foto se refiere al pasado efímero. El instante fotográfico es irrecuperable, en ese sentido es decisivo. La fotografía es profundamente democrática: trata a todos los sujetos y objetos por igual. Permite así estudiar la esencia abstracta de la variación humana, es decir, de los tipos humanos diversos. El mundo puede ser visto, mirado, estudiado a través de imágenes fijas. Permite analizar la realidad social desde una cierta distancia. Como con la letra impresa, la fotografía fija (traducción de still photography) permite que algo pueda ser vuelto a ver. Por eso genera nostalgia. Las fotos antiguas, amarillentas, romantizan un pasado todavía visible en dos dimensiones y en formato reducido.

La fotografía es una herramienta del análisis social ${ }^{3}$. Se dispara (la cámara) para congelar un instante o momento decisivo que permite luego ser visto, revisto, interpretado. Pero la fotografía es además un acto social. Se sacan fotos de los ritos de paso: bautizos, comuniones, bodas, viajes de luna de miel, graduaciones escolares, cumpleaños de los hijos/as, viajes a Mallorca o a Grecia. En otras culturas se fotografía el primer día de escuela, la primera visita al dentista, etc. ${ }^{4}$. Antes, incluso, se fotografiaba a los muertos/as; ya no se hace. La

${ }^{1}$ En estas pocas páginas se reconoce la influencia de muchas personas. El primer agradecimiento va para la antropóloga María Jesús Buxó, por sus ideas y ayuda. A Marta Caballero, por sus intuiciones fotográficas. El Departamento de Antropología de la Universidad de Adelaide, en Australia, supuso una gran ayuda. Otra influencia muy especial es la de Carmelo Pinto, con quienes hemos enseñado y discutido muchas de la teorías y fotografías. De las influencias más recientes hay que agradecer las sugerencias fotográficas de Tànit Pons, Rocío Carrera, y Marga Marí-Klose. Muchas gracias también a Jordi Caïs, Xavier Escandell, y Francisco J. Granados. Algunas ideas de este estudio se discutieron antes en la University of Adelaide (Australia), en la Universidad de Málaga (gracias a Juan del Pino), en la Universidad del País Vasco (gracias a Benjamín Tejerina y María Teresa Bazo), en la Universidad Pública de Navarra (gracias a Bernabé Sarabia) y en la Universidad de La Coruña (gracias a Benjamín González y Amparo Almarcha). Una influencia estraordinaria fue la del Center fort Creative Photography en la University of Arizona. Muchas gracias también a las ideas de Stanley Brandes, de la University of California Berkeley, y a Mónica Ramírez en la Universidad de Arizona. Ojalá que tanto estos colegas como los/as estudiantes de esas universidades sigan adelante con sus intuiciones fotográficas y sociológicas. Las mejores gracias van para Leica M6 con Summilux $50 \mathrm{~mm}$., y la vieja Nikon F4 con AF Nikkor $50 \mathrm{~mm}$. (ambas, 1:1,4); las dos nos han enseñado a mirar la sociedad.

2 «Fotografía» es un concepto ambiguo, pues lo mismo se refiere a la disciplina como a una foto concreta. Para evitar la confusión aquí se utiliza «Fotografía» con mayúscula para referirse a la profesión, carrera, o ciencia (arte); "fotografía», para la técnica y el instrumento de análisis visual de la realidad social, y «foto», para un negativo positivado sobre papel fotográfico.

3 Un excelente ejemplo en España es el libro de María Ángeles Durán y Carlos Hernández Pezzi, La ciudad compartida (Madrid, Consejo Superior de Arquitectos de España, 1998), 2 vols.

${ }^{4}$ Algunas máquinas nuevas, como las de advanced photo system, permiten poner rótulos o títulos a las fotografías. Es interesante el catálogo de títulos prefabricados, que indica las posibilidades estandarizadas de escenas fotografiables según la industria. Estos son, por ejemplo, algunos 
fotografía es un rito social o al menos parte de un rito, tanto como es una defensa contra la ansiedad. Se viaja fotografiando para sentir que se hace algo, que se trabaja. La cámara es además un instrumento de poder, agresivo, que enfoca y dispara... pero que no mata sino que apropia.

\section{TEORÍAS SOCIOLÓGICAS SOBRE FOTOGRAFÍA}

Una cierta tradición considera que la fotografía tiene un contenido frívolo dentro de la investigación social. Algunos periódicos o publicaciones serias nunca, o casi nunca, presentan fotos: Le Monde, The New York Review of Books y Revista de Occidente, o tantas otras revistas profesionales sociológicas. A veces sustituyen las fotografías por dibujos a plumilla, con un planteamiento ultraclásico peculiar. La fotografía se considera equívoca, desinformante, de dudoso significado o simplemente falsa. Quizá se piensa que es demasiado real. Es una invitación a la fantasía, a veces incluso erótica. Una foto sin pie de foto no se suele entender. Curiosamente en un mundo lleno de imágenes la palabra sigue siendo importante. La imagen es además una mirada de adultos y de varones al mundo exterior. El mundo se hace accesible a través de las fotos.

Es difícil establecer teorías convincentes, o elaboradas, en base solamente a fotos. Las fotografías tienen significados múltiples y no está clara la forma en que pueden ser interpretadas. Lo mismo podría decirse de un texto escrito, o de unas tablas de datos, pero no se suele reconocer tan a menudo. Existe además una dificultad considerable al tratar de unir texto y foto. Muy pocas tesis doctorales o investigaciones en las ciencias sociales incluyen texto y fotos a un nivel de igualdad. Si lo hacen es a un nivel desequilibrado de importancia. Las fotos, pocas, suelen ser una mera ilustración del texto. No se suele desarrollar una teoría con imágenes. Quizá eso se deba a la dificultad de transmitir mensajes abstractos elaborados en base a fotos. La relaciones políticas y económicas son difíciles de fotografiar. Las estructuras de poder y desigualdad están escondidas, no pueden fotografiarse. Muchos de los temas vitales más importantes son invisibles, ocurren a puerta cerrada, a oscuras, no pueden ser fotografiados. Pero eso no implica que la fotografía no sea útil para avanzar el conocimiento o formular teorías. Curiosamente los fotógrafos/as cometen el error contrario: presentan muchas fotos con muy poco texto, y a menudo con un texto que es

de los de la cámara Fuji «Endeavor Fotonex MRC»: navidad, cumpleaños, vacaciones, luna de miel, boda, graduación, familia, fiesta, aniversario, amigos, acto escolar, viaje, te quiero, gracias, felices pascuas, feliz cumpleaños, felicidades, feliz navidad, festival, primer día de colegio, tour, año nuevo, pascua de resurrección, feliz año nuevo, reencuentro, día del padre, día de la madre, recuerdos, y bautismo. En otros idiomas se incorpora también hanukkah y party. Esta posible lista de treinta rótulos (en doce idiomas diferentes) expresa bastante bien el catálogo de sucesos fotografiables dentro de una sociedad contemporánea, aunque se realiza con un elevado nivel de ingenuidad familista. 
simbólico o meramente estético (citas de Confucio, Shakespeare, la Biblia, poesías, letra de los Beatles).

Hay toda una tradición comprometida de la fotografía. La foto puede ayudar a conocer y a denunciar situaciones sociales de hambre, violencia, carencias u opresión. La fotografía puede también colaborar a un conocimiento crítico de la sociedad. Es posible un conocimiento profundo a través de la emoción, y no sólo a través de los datos. Se trata, pues, de conocer para reformar, para cambiar. La foto se utiliza además en una tradición de diseñar pósters y collages que sirven de propaganda política y comercial. La fotografía puede ser utilizada para explicar visualmente los males sociales, los problemas de la sociedad. Permite describir comunidades, familias e incluso provocar la acción social. Un campo novedoso de investigación es investigar qué ocurrió con las personas que aparecen en una foto. Personas perseguidas, bombardeadas (como en las fotos de Robert Capa), que huyen, que pasan hambre pueden ser vueltas a fotografiar - si es que viven - unas décadas después. Esta forma de investigar apenas se ha desarrollado. Las consecuencias de ese tipo de investigación es un instrumento que sirve para unir los aspectos macro con los micro de la sociología. Seguramente reafirmaría la idea de que la vida es bella y cruel al mismo tiempo.

La teoría fotográfica aplicada al análisis de la sociedad está realmente subdesarrollada. Se acepta la Fotografía como arte, como química, a veces incluso como denuncia, como pasatiempo, pero no como Sociología. Sin embargo, la Fotografía contribuye sustantivamente a la construcción de la realidad social. Cada vez es más importante la imagen en las ideas que se tienen de la sociedad, de los roles sociales, de las normas sociales. Aunque la teoría fotográfica no se ha desarrollado apenas hasta ahora, sí hay sociólogos importantes que se han dedicado a temas fotográficos. Erving Goffman tiene un libro importante sobre Gender Advertisements, o los roles femeninos aprendidos a través de las fotos (1979) . Howard Becker es el sociólogo que seguramente más ha escrito sobre fotografía (entre 1974 y 1986) ${ }^{6}$. Pierre Bourdieu tiene un libro esencial sobre fotografía como "un arte medio» (en 1965)7. Desde el ensayismo sociológico, Susan Sontag ha escrito un excelente libro sobre Fotografía (en 1977) Otros sociólogos/as sí han tratado el tema de la Fotografía, pero no es todavía un tema legítimo de análisis, al mismo nivel que los datos estadísticos o el texto.

5 Erving Goffman, Gender Advertisement (Nueva York: Harper \& Row, 1979), 84 pp.

${ }^{6}$ Ver, sobre todo, Howard S. BECKER, Exploring Society Photographically (Evanston, Illinois: Mary and Leigh Block Gallery, Northwestern University, 1981), 96 pp., y Howard S. BECKER, Art Worlds (Berkeley: University of California Press, 1982), 392 pp. Ver también varios capítulos en Doing Things Together (Evanston, Illinois: Northwestern University Press, 1986), pp. 221317.

Pierre Bourdieu, et al., Un art moyen: Essai sur les usages sociaux de la photographie (París: Les Éditions de Minuit, 1965), 361 pp. Otras ideas novedosas aparecen en su librito, Sobre la televisión (Barcelona: Anagrama, 1997), 140 pp.

${ }^{8}$ Susan SONTAG, Sobre la fotografía (Barcelona: Edhasa, 1981), 219 pp. 
Se habla de Fotografía como ciencia y como arte. Las bibliotecas incluyen dentro de la sección de "Fotografía" libros de historia de la fotografía, manuales de técnicas de utilización de cámaras y de revelado, así como una serie extensa de libros de autor (de fotógrafos/as famosos). Fotografía se refiere, pues, al arte o la ciencia, mientras que foto es la forma coloquial en español de referirse a la fotografía o de mencionar una imagen - se dice una fotografía o foto- concreta. Igual de interesante puede ser una fotografía de un fotógrafo/a importante que de una persona anónima. Para sacar fotos no se necesita un título especial ${ }^{9}$. Pero se habla de fotógrafo (varón o mujer), cuando es un/a profesional que se dedica a la fotografía, que vive de ella. Se habla de amateur, cuando no es un fotógrafo/a profesional, pero es persona especialmente obsesionada por las cámaras y por sacar fotos, normalmente «artísticas» (es decir, enfocadas, centradas, bonitas). Los ritos de paso pueden ser fotografiados por fotógrafos profesionales, pero a menudo los familiares y amistades se encargan también de fotografiar esas situaciones sociales. Existe un formato detallado de lo que hay que fotografiar y lo que no. Las bodas son el rito social con especificaciones más claras de lo fotografiable e incluso en qué orden.

Hay discusiones tópicas como las de fotografía en color versus blanco y negro o la de fotografía (fija) respecto del vídeo o película (cine). Esta segunda discusión es importante. La fotografía no es mejor ni peor que el vídeo. Son estrategias distintas. Ambas contribuyen al conocimiento de la realidad. La fotografía fija describe el pasado, un instante decisivo apenas perceptible para el ojo humano. Pero se puede volver a ver muchas veces, a pensar sobre la foto, incluso a investigar. La película o vídeo puede suponer varias decenas de fotos por segundo. No se fija tanto en el pasado, sino más bien en el futuro: lo que va a pasar. Algo va a suceder continuamente y se trata de preverlo, de ansiosamente esperar a ver qué sucede. Se puede congelar una imagen de vídeo, pero no se suele hacer. Se visiona seguido, sin detenerse en una imagen. En ese sentido las fotos (32 por segundo) se ven deprisa. Van a tal velocidad que no se pueden pensar por separado; incluso a veces no se «ven» todas, sino sólo subliminalmente. Foto y vídeo son, pues, instrumentos y estrategias diferentes. Ambas utilizan la imagen, una cámara y un cameraman (horrible anglicismo) pero con metas distintas.

La foto no es sólo la foto. Es usual pensar que en una fotografía sólo aparecen las personas que están en la imagen. Pero al menos está también (aunque no se vea) la persona que sacó la foto. Es un personaje importante. En fotografía (y en vídeo) conviene diferenciar entre el fotógrafo/a, la cámara y el espectador/a u observador/a. Los tres (fotógrafo-cámara-espectador) miran, enfocan incluso, pero tienen ideas diferentes de lo que buscan, y sacan conclusiones distintas. Quizá la cámara es más inerte, pero los aspectos técnicos son también importantes. No "ve» lo mismo un objetivo de $50 \mathrm{~mm}$ que un gran angu-

9 En español se dice «sacar» fotos, por hacerlas pero no por revelarlas. A veces se habla de «tirar fotos». 
lar (de 35, 28 o $21 \mathrm{~mm}$ ). El objetivo estándar de $50 \mathrm{~mm}$ tiene un ángulo de campo de unos 45 grados, similar al ojo humano. Un gran angular de $28 \mathrm{~mm}$ tiene un ángulo de campo de 76 grados, es decir, que «ve» un $69 \%$ más que el ojo humano. La cámara puede ver más que el ser humano, y sobre todo mejor enfocado. También es importante la persona (o máquina) que revela la foto, sobre todo en blanco y negro, donde existe un mayor poder de la persona que realiza el revelado.

Sorprende la idea de que una cámara ve más que el ojo humano. Un objetivo de $50 \mathrm{~mm}$ se acerca mucho a la visión del ojo humano. Sin embargo, un objetivo gran angular de $28 \mathrm{~mm}$ ve bastante más que el ojo humano, más ángulo. Pero las personas pueden ver por el rabillo del ojo (las cámaras, no), desenfocado y borroso, pero notan cambios, colores, señales amenazantes. Una foto tiene la propiedad de que puede estar toda ella enfocada. Cuando un ser humano mira, enfoca una parte limitada de la escena. El resto, a su alrededor, aparece menos nítido, y cuanto más se aleja del punto de enfoque es más borroso. Una foto (bien enfocada, con luz, y con profundidad de campo) puede aparecer totalmente enfocada, por ejemplo, desde la persona de pie a la entrada de una iglesia hasta la campana de la torre. En ese sentido, una foto no es lo que vemos, sino algo parecido, pero con características distintas. En las fotos los colores no son de verdad, sino resultados químicos que se asemejan a la realidad. Por eso los seres humanos aparecen «raros» en las fotos. Las personas apenas se reconocen a sí mismas en las fotos. "No he salido bien en esta foto", se suele decir. Las personas apenas se ven a sí mismas (salvo en los espejos de los cuartos de baño por la mañana). Les cuesta, pues, reconocerse.

Las fotos explican, hacen sentir algo y ordenan el conocimiento. Son tres procesos de elaboración del conocimiento importantes. Suponen una forma peculiar de conocer la realidad social, pero también de crearla. La publicidad aprovecha esta característica de construcción de la realidad social y el potencial de generar normas sociales. En la cultura llamada "occidental» se cree mucho en las palabras y poco en las imágenes. Ocurre al revés en la cultura "oriental» que es más intimista y pictórica ${ }^{10}$. En el mundo contemporáneo cada vez hay más imágenes, y éstas tienen más poder sobre nuestras vidas. Por eso es tan importante entender de Fotografía y de fotos.

\section{ANÁLISIS SOCIAL DE FOTOGRAFÍAS}

Cualquier investigador/a social debe aprender a distinguir tres tipos distintos de fotos: fotos-ventana, fotos-espejo, y fotos-regla. Toda foto corresponde a una de estas tres categorías. A menudo una misma foto puede tener caracterís-

10 En japonés, por ejemplo, toda la escritura kanji es ideográfica, al estilo de la china (de donde proviene). Refiere, pues, de forma estilizada a la realidad visual de la noción descrita. 
ticas de dos o tres tipos. Un paso importante para saber de Fotografía y de Sociología es entrenarse en distinguir estos tres tipos distintos.

La ventana representa una foto que está abierta a la realidad. Al abrir una ventana se ve el exterior. El objetivo de la foto es mostrar el mundo visible a la luz, reproducirlo exactamente, mejor que en un cuadro. Al igual que una ventana si no hay luz (si la ventana se abre en una noche cerrada) se ve poco o nada. La fotos son muy exactas, y el paisaje o escena que se fotografía es una visión real, empírica, detallada de la realidad. Las fotografías reproducen la realidad con exactitud. No pueden ser falsas, a menos que se truquen o que la realidad sea equívoca. Son como un testigo presencial, policial, de un hecho. Se suele utilizar en casos penales como evidencia. La ventana abierta ¡es una reproducción exacta de la realidad? Al menos lo es de una parte de la realidad, precisamente la porción que en ese momento estaba enfocada por el fotógrafo/a. Pero una fotografía (o una ventana abierta) dice poco de la parte de atrás de la casa o de la realidad detrás de los árboles. Hay, pues, una selección de la realidad previa: lo fotografiable, lo que se desea fotografiar, lo que se puede fotografiar, lo que realmente se fotografía, y siempre que haya luz.

Se dice que una imagen vale más que mil palabras, es decir, más que cuatro páginas de texto. La foto-ventana es un testimonio de un mundo que desaparece, que a lo mejor nunca más volverá a ocurrir. Los mineros, o los agricultores, fotografiados por los fotógrafos del siglo XX (como hace Sebastião Salgado) son seguramente los últimos trabajadores industriales de su tipo en la historia de la humanidad. Se fotografían edificios que van a desaparecer y no sólo los rascacielos nuevos que se construyen. Sabemos así cómo fueron construidos y cómo fueron antes de derruirlos. La fotografía es especialmente útil para recordar la historia.

Los espejos reflejan los sentimientos del propio fotógrafo/a. Las fotos-espejo representan una estrategia de expresión. Proyectan lo que el fotógrafo/a siente ante una realidad social. La fotógrafa saca esa foto precisamente para hacer sentir a otra persona (espectadora) de la misma manera. Las fotos de petit bonheur, de pequeña felicidad, durante la segunda postguerra mundial pretenden hacer olvidar las secuelas de la guerra, así como las situaciones de hambre y destrucción. Enfocan los contrasentidos chistosos o mínimamente paradójicos de la vida cotidiana, de la vida moderna a lo Sempé, olvidándose de las catástrofes. Las fotos de pobres pueden tratar de llamar la atención sobre esa población marginal, o quizá sobre lo que se denomina "la pobreza digna». Algunas personas son pobres, pero tienen una mirada limpia, honesta. A través de la televisión o de las revistas la fotografía hace llegar las injusticias del mundo hasta el cuarto de estar. Se ven entonces en el propio hogar asesinatos o imágenes de extrema pobreza o injusticia, que suceden en lugares remotos del planeta. A veces eso ocurre casi de forma instantánea, gracias a que ya no sólo viajan a través del espacio las palabras o el texto, sino también las imágenes.

La foto-espejo supone una transferencia desde el fotógrafo/a al espectador/a. Trata de comunicar visualmente un pensamiento íntimo. La foto no es 
más que una excusa. El mensaje es subliminal, indirecto, o simplemente sentimental. El fotógrafo/a trata de persuadir de algo a cualquier espectador/a. Algo similar ocurre con la pintura, pero sin utilizar necesariamente la realidad. Los espejos valen para investigar la naturaleza humana, los valores vitales de las personas. La realidad real no importa tanto como lo que ésta comunica. El espejo puede utilizarse entonces como material autobiográfico, incluso para el análisis psicoanalítico de una persona o un grupo social. Pero siempre es necesaria una teoría o un paradigma para su interpretación. Así, en Gender Advertisements, Goffman no presenta una lista cualquiera de fotos de mujeres y varones en roles distintos, algunos de ellos publicitarios (es decir, ficticios). El sociólogo canadiense desarrolla un marco teórico conceptual que trata de demostrar con las fotos. Este marco conceptual - como en The Americans, de Robert Frank - puede ser sutil, múltiple, poco definido, pero no hay duda de que existe y está laboriosamente trabajado ${ }^{11}$.

La cualidad principal de una fotografía es que sea inquietante, extraña. Dice o sugiere algo, pero no se sabe exactamente qué es. No queda claro a qué se refiere o lo qué se está fotografiando. Si no hay pie de foto es difícil obtener una interpretación rápida de la foto. Inquietante es pues una característica positiva en el arte, en la fotografía, pues estimula interpretaciones múltiples de la realidad ${ }^{12}$. El fotógrafo/a dispara y desaparece, pero deja su puesto para que sea ocupado por el espectador/a. Curiosamente el espectador ocupa luego exactamente el mismo sitio en que estaba antes la fotógrafa. Existe pues una comunicación refleja entre ambas personas. De eso tratan precisamente los espejos.

No todas las fotografías son espejo o ventana, aunque sí lo son la mayoría de ellas. Hay algunas fotos, sobre todo las publicitarias, que se producen desde el mundo de la irrealidad o la fantasía, y que se pueden denominar reglas o normas. Suponen un sistema o estrategia de control social. Esas fotos no sólo tienen un significado sino que producen significado. Dicen cómo otra persona debe de conducirse o actuar, señalan lo que es bueno y malo. Dictan la moda: cómo hay que vestir, pensar, comprar, sentir, desear, relacionarse, beber, viajar,

${ }^{11}$ Robert Frank, The Americans (Nueva York: Grove Press, 1959), la primera edición es Les Américains (París: Robert Delpire, 1958). Es la serie más importante de fotos describiendo un país concreto, con una perspectiva externa. Se ha utilizado aquí la reedición de 1986 (Nueva York: Pantheon Books, 179 pp.). Incluye una introducción de Jack Kerouac (el famoso autor de On the Road, 1957). Es una interpretación de la sociedad de Estados Unidos veinte años después de American Photographs de Walker Evans (MoMA, 1938, considerada como la primera visión fotográfica global de la sociedad estadounidense; 37 fotos). Frank es mucho más crítico e innovador. El trabajo de campo le llevó dos años - 1955-1956 - viajando a través de los Estados Unidos con una beca Simon Guggenheim (la primera concedida a un extranjero; Robert Frank era suizo, nacido en el año 1924). Después de la exposición fue duramente criticada y rechazada. Con los años es considerada la serie de fotos más influyente en la Fotografía contemporánea. El presente portafolio contiene 83 fotos, todas en blanco y negro.

${ }_{12}$ En este caso, como la excelente obra autobiográfica del sociólogo Esteban Pinilla de las Heras, La memoria inquieta (Madrid: Centro de Investigaciones Sociológicas, 1996), 307 pp. 
comer, hablar, etc. Suelen establecer una norma idealizada. A menudo existen varias normas en una misma foto de este tipo. Quizá son mensajes distintos para personas diversas. Por ejemplo, muchas fotos publicitarias que tratan de vender algo (un coche, una lavadora, incluso cigarrillos) utilizan la foto de una mujer guapa, provocadora. Es obvio que el mensaje no es igual para un espectador varón que para una mujer. Aunque curiosamente en ambos casos puede conseguir su objetivo: vender más ese producto que anuncia. Las fotos-reglas son típicas de anuncios de todo tipo, de publicidad, revistas, incluso televisión. Señalan lo que otra persona debe hacer; y el castigo que va a sufrir si no lo hace. Son tipos ideales que incluyen el mensaje del contratipo. Es decir, dictan una norma social, la contranorma, y a menudo incluso el castigo si no se sigue la norma.

Cualquier foto pertenece a uno de estos tres tipos - ventana, espejo, regla - o es una combinación de factores de los tres tipos en proporciones distintas. Igual que los sueños son siempre una realización de deseos, las fotografías no sólo describen la realidad sino que la construyen. La fotografía (una foto, o el arte de la Fotografía) no es nunca inocente. Es parte de la cultura, de la sociedad y mantiene un protagonismo determinado dentro de esa cultura. Cada vez más una foto tiene diversos niveles de realidad. La Sociología enseña dos cosas: a mirar fotos y a construirlas. Cuando se dedica tiempo a observar y analizar una foto, el significado de esa foto cambia, a veces radicalmente. Basta con observar una imagen o una foto con ojo sociológico para que el significado (y el placer) de mirar una foto se transforme.

\section{DOS FORMAS DE MIRAR}

Hay dos formas de mirar fotos: rápida y lenta. No se refiere aquí a ver pasar las fotografías a cuarenta o cincuenta imágenes por segundo. Se trata de fotos ya fijas, que se pueden hojear, echarles un vistazo, o analizarlas despaciosamente y a voluntad. No hay una máquina que nos las pase automáticamente. Eso vale para cualquier foto. Pero el resultado es desigual.

Al hojear una revista, leer un periódico o conducir por la ciudad se pasa a menudo inadvertidamente por delante de decenas de fotos. A cada una se le echa un vistazo, a veces por el rabillo del ojo. Es cuestión de segundos. Con ese sistema de mirada rápida, el espectador/a reconoce la foto y seguramente el mensaje directo que suele contener. Se apropia del significado de la foto y queda tranquilo/a. Apropiándola se ejerce poder sobre la foto. En el cerebro humano se produce una explicación inmediata y fácil del contenido de la foto. Eso produce satisfacción: se han realizado los deberes bien. El premio es el supuesto poder sobre la foto. En el ser humano ese acto produce placer, asociado con un cierto goce voyeurista. Es como si se estuviese viendo algo (el mundo) por el ojo de una cerradura. Ver fotos, los «santos» de un libro, genera una 
cierta alegría o satisfacción. Como señala Rose K. Goldsen, mirar imágenes supone una fascinación especial en nuestra cultura ${ }^{13}$.

Pero si se contempla una foto de forma lenta la situación cambia. El experimento es mirar una misma foto durante minutos, incluso media hora o más. Entonces se descubren otros significados, más o menos ocultos. Pueden ser significados generados voluntariamente por el fotógrafo/a o incluso inadvertidos por ese fotógrafo/a. Se establecen relaciones con otros contextos, entornos, culturas, tradiciones culturales, normas sociales, etc. Algunas fotos chocan o inquietan sin que se sepa por qué; como muchas que anuncia la compañía Benetton. Ese choque o sorpresa está buscado deliberadamente por los/as anunciantes para llamar la atención. Si se mira despaciosamente una foto se entiende mejor su significado, y el orden de las fotos en un reportaje o en un estudio. El orden, o posición de una foto en el texto, es siempre importante, pues entre muchos órdenes diversos, alguien (no necesariamente el fotógrafo/a) escoge uno concreto. Cuando es el propio fotógrafo/a aporta nuevas claves para entender la foto.

En una mirada lenta se va perdiendo el poder sobre la mirada y sobre la foto. Llega un momento en que los ojos se sienten confusos, no saben a dónde mirar. Se pierde progresivamente el poder sobre la foto -inicialmente apropiada - para terminar siendo poseído/a por la foto. Inevitablemente, cualquier foto, sobre todo si es «importante», hay que ponerla en el contexto de la tradición fotográfica, en verdadero diálogo con el resto de las fotos de la historia de la humanidad; comparándola incluso con pinturas, cuadros, arquitectura, cultura. No es verdad que las fotos sean robinsones crusoes aislados. Cada foto se entiende en el contexto de los procesos fotográficos de las últimas décadas y en general del arte. Hay ciento cincuenta años de historia de fotos «importantes», y las personas que se dedican a esta especialidad (como cualquier otros/as profesionales) saben identificar cuáles son esas fotos, las recuerdan, las tienen fijadas mentalmente en su cabeza, aparecen en los libros de historia de la fotografía. Recuerdan y comparan. El proceso de conocimiento es parecido a la pintura, escultura, arquitectura, diseño.

Una foto vista lentamente termina produciendo ansiedad, intranquilidad, inquietud, incluso desconcierto. La foto recupera su poder sobre el observador/a. Quizá es que quien recupera el poder sea el fotógrafo, que después de sacar la foto desapareció para dejar su puesto al observador/a. Pero el fotógrafo/a está allí cerca, agazapado, esperando la reacción del observador. Cuando se mira detenidamente una foto cualquiera se intuye o se entiende mejor al fotógrafo/a, así como el proceso de construcción de la realidad.

La idea fundamental es que la fotografía es una estrategia para el conocimiento de la realidad social. Es una ciencia blanda, artística, lábil, pero con un soporte nítido, duro, electrónico y químico. Ser un buen fotógrafo no es fácil;

13 Rose K. Goldsen, The Show and Tell Machine: How Television Works and Works You Over (Nueva York: A Delta Book, 1978). 
«leer» fotos tampoco lo es. No es problema de tener una buena cámara, sino un buen ojo y un mejor cerebro. Hay una estrategia para producir un portafolio fotográfico como hay una estrategia para ver fotos o para escribir un buen libro. En el presente artículo interesa saber qué es lo que se quiere ver o mirar. En otro trabajo se presentan ideas de cómo producir fotos sociológicas.

Hay normas informales en fotografía que permiten conocer los límites o el marco. Las fotos no deben estar trucadas, ni retocadas, ni alteradas sin previo aviso. No deben estar del revés, ni cortadas, ni ampliadas sólo en una porción. Una foto debe dar una información real de lo que se fotografía. Por eso cada vez con más frecuencia se pide que la foto revelada incluya todo el negativo, con los bordes negros, sin alterar ${ }^{14}$. Una cierta ética es pedir permiso para fotografiar, como lo hacen otros especialistas sociales para entrevistar (sociólogos, antropólogos, médicos). Muchas veces se suele pedir permiso después de sacar la foto. La mayoría de fotos reproducen el ojo humano, es decir, fueron sacadas con un objetivo de $50 \mathrm{~mm}$, similar a lo que el ojo capta ( 45 grados). La distorsión que produce un gran angular, o la falta de intimidad de un teleobjetivo es irritante para los/as mejores profesionales.

La polémica entre el uso del blanco-y-negro o el color no se ha zanjado todavía. La fotografía clásica, carismática, noble, es casi siempre en blanco y negro. La discusión se refiere más a la falsificación de la realidad. Ambos sistemas (grises y color) falsifican la realidad. Primero, el gris, porque la vida no es gris sino en colorines. Segundo, el color, porque no corresponde al color de verdad. El de las fotos es un color químico ligeramente irreal. La gama de grises reproduce una gradación más suave, más diversificada de los tonos. El color apenas deja ver las tonalidades de grises. El blanco y negro permite que el fotógrafo/a mismo lo revele y por lo tanto mantenga un cierto control sobre su obra; en el color eso es casi imposible. Cualquiera de los dos métodos tiene sus problemas.

Son más importantes los problemas prácticos. Una foto necesita luz y tiempo. Ambas características son sociológicamente peculiares: no sobran, no siempre existen. Seguramente algunas de las situaciones o procesos más importantes de la vida humana son infotografiables. En el terreno práctico es posible reacciones violentas por parte de personas fotografiadas sin avisar. No es posible vivir y fotografiar al mismo tiempo. Un buen fotógrafo/a viaja, vive, duerme con la cámara; casi como un militar con la pistola. Pero conviene deslidar el rol de ciudadano normal y de fotógrafo.

${ }_{14}$ Pero no es siempre así, incluso con fotografías famosas. La célebre foto de los tres guardias civiles en Deleitosa, realizada por Eugene Smith en su reportaje para la revista Life, es en realidad una parte del negativo, cortado en la ampliación para acentuar el dramatismo y el contraste. Los otros 37 negativos no escogidos para el reportaje impreso incluyen los tres mismos guardias civiles pero en una representación bastante más suave y menos dura. Es un caso claro de modificación de un negativo para lograr un mensaje determinado. Sólo es posible darse cuenta viendo los contactos de los negativos originales. Véase, Jesús M. DE MiguEL, Imágenes del cambio social (Barcelona: Universitat de Barcelona, 1999, manuscrito no publicado). 
Toda foto pide una explicación, un pie, una información sobre lo que se fotografía, el fotógrafo/a, la cámara y su objetivo, el negativo, velocidad, apertura, fecha, lugar, etc. Sin ello el espectador/a está algo perdido, confuso. Pero casi nunca - ni siquiera en los llamados libros de fotos- se ofrece tanta información. Hay que reconocer que todas las fotos (incluso cuando se identifica el sujeto exacto) son ambiguas: tienen significados e interpretaciones múltiples. Otro problema es que existe una discontinuidad entre el instante fotografiado y la foto revelada y expuesta. Ha pasado el tiempo, y por ello el significado es distinto, ha cambiado. El esfuerzo consiste en averiguar lo que el fotógrafo/a trata de fotografiar y lo que el fotógrafo/a no quiso fotografiar. Todo esto debe ponerse en el contexto de lo que es posible fotografiar, ya que hay situaciones, procesos, sentimientos, olores, sonidos, oscuridades, situaciones íntimas que no son fotografiables. Otras situaciones son tabú y se evita su fotografía.

Existe una discusión sobre las fotos malas y buenas, las fotos profesionales y las de aficionado/a, en qué consiste el canon en fotografía. Esa polémica merece un libro aparte. Los/as clásicos están menos claros en Fotografía que en Sociología o en Antropología. Comte, Marx, Durkheim, Weber, Simmel, Pareto, Freud son unánimemente considerados los padres fundadores de una ciencia social. En Fotografía no hay una lista universal tan precisa. La definición del canon, lo que es bello, bueno, inmortal, es bastante debatible en Fotografía. Se ha impuesto, claro está, un canon occidental, anglosajón. Pero desde las ciencias sociales es posible discutirlo, retarlo, demostrar su etnocentrismo, clasismo, sexismo. El sociólogo Becker discute el tema del canon como uno de los más fascinantes en el terreno del arte ${ }^{15}$.

Pero la dificultad mayor es la de cómo unir foto y texto. Los/as científicos sociales somos reacios a esa unión. No se enseña cómo realizarla; hay poca investigación sobre la forma de hacerlo. La información en la sociedad actual se presenta en foto-y-texto, pero no se investiga con foto-y-texto. El discurso fotográfico se puede enseñar y aprender, como cualquier otra disciplina. Dar sentido a una foto es una forma de trabajar, a menudo costosa, estresante, fatigante. Cualquier foto —incluso las fotos «malas»— enseña sobre la realidad social, sobre la naturaleza humana también, y todo ello a diversos niveles. Una foto «mala» pero interesante vale más que muchas «buenas». La vida es menos nítida, centrada y enfocada que la mayoría de las fotos.

La inmensa mayoría de fotógrafos/as no saben nada de ciencias sociales. Tienen buen ojo, mejor olfato a veces, y sensibilidad social; pero no analizan críticamente, ni de forma disciplinada la estructura de la sociedad. La Fotografía es una estrategia de conocimiento que requiere disciplina intelectual, lo mismo o más que cualquier otra ciencia. Se está en el alba de una nueva gene-

15 Howard S. BECKER, "Photography and sociology», Studies in the Anthropology of Visual Communication 1 (1974), pp. 3-26; Howard S. BECKER, "Do photographs tell the truth?», Afterimage 5 (febrero 1978), pp. 9-13. Se puede comparar con el canon en la literatura, por ejemplo, Harold Bloom, The Western Canon: The Book and School of the Ages (Nueva York: Harcourt Brace, 1994), 578 pp. 
ración de científicos/as sociales interesados seriamente en fotografía, que utilicen la fotografía para analizar la realidad social. De ese nuevo análisis de la sociedad es posible obtener nuevas teorías y progresos. Es una tarea para el siglo XXI. El dicho de Robert Capa de que si tu fotografía no es buena es porque no te acercaste lo suficiente, debe aplicarse ahora a los/as científicos sociales: si quieren saber más de la realidad social es preciso que estudien Fotografía, seriamente, y sobre todo que vean y hagan muchas fotos ${ }^{16}$. El reto fundamental es el de combinar foto y texto en la investigación social.

\section{ANÁLISIS DE LA REALIDAD SOCIAL}

La Sociología ha olvidado la imagen o quizá es que no la ha descubierto todavía. El objetivo de la Sociología de la Fotografía es estudiar el impacto de la imagen fotográfica en el análisis social (sociológico y antropológico, fundamentalmente). Se trata de analizar la fotografía como una realidad, organización e institución social. Una Sociología de la Fotografía estándar se organiza en temas que cubren de forma ordenada los aspectos básicos que sobre el tema se imparte en cualquier programa universitario en el mundo ${ }^{17}$.

La Sociología de la Fotografía no conviene estudiarla de forma cronológica ni histórica, sino analíticamente. Lo más apropiado es partir del estudio de la imagen fotográfica, su evolución en España y en el mundo. Luego hay que desarrollar las teorías sociológicas básicas sobre la Fotografía. Se trata de investigar la utilización de la fotografía en las ciencias sociales, con temas sobre su uso en antropología, sociología e historia. Luego se puede discutir la creación de fotos populares y la importancia de la fotografía en la vida familiar y doméstica de las últimas décadas. Se suele dar importancia al estudio fotográfico de comunidades. Otro aspecto central es la utilización de la fotografía para el análisis de las desigualdades sociales. Conviene conocer algunos estudios fotográficos novedosos de la realidad social, y especialmente los nuevos proyec-

${ }^{16}$ Robert Capa (su nombre real era Endre Ernö Friedmann, nacido en 1913 en Budapest) se acercó tanto que murió al estallarle una mina haciendo de corresponsal de guerra en Indochina, en 1954. El consejo vale, pues, mucho, pero como todo en la vida puede ser peligroso. Nos quedan sus fotos inmortales y su Leica agujereada.

${ }_{17}$ Muchas de las ideas aquí expuestas parten de una asignatura impartida titulada La Fotografía en las Ciencias Sociales. Es un curso de doctorado que en España se enseñó por primera vez en el año académico 1991-92 en la Universidad de Barcelona. En la actualidad forma parte del Programa de Doctorado de Sociología Avanzada de la misma Universidad (un programa bianual, de 32 créditos) y se enseña en los años impares. Es una asignatura alternativa (en años) con la de Vídeo en las Ciencias Sociales que también se enseña en el mismo Programa de Doctorado (por Carmelo Pinto). Los profesores son Jesús M. de Miguel (catedrático de Sociología de la Universidad de Barcelona) y el propio Carmelo Pinto. Han sido profesores también Omar G. Ponce de León, de la Escuela Activa de Fotografía de México, doctor en Sociología por la Universidad de Barcelona y actualmente jefe del Departamento de Posgrado de la Universidad Autónoma del Estado de Morelos, en Cuernavaca, México. También ha colaborado activamente como profesor Antonio Fernández Carracedo, de la Agrupación de Fotografía de Castelldefels. 
tos que combinan texto escrito con fotografía. De ahí se pasa lógicamente a los proyectos de cambio social y político en que se utilizan fotografías. La foto es también noticia e información, por lo que es importante estudiar la tradición del fotoperiodismo. Otro tema importante es la fotografía como institución social y como mercado organizado. Se debe mencionar - aunque no es necesario estudiarlo en detalle - la foto en movimiento, especialmente la fotosecuencia audiovisual. Interesa la forma en que España es vista desde la perspectiva de los/as fotógrafos extranjeros. También se debe discutir la posible huella de España en la fotografía latinoamericana. Es interesante realizar estudios de casos y sobre las técnicas especiales para realizar portafolios.

Conviene empezar el estudio sociológico de la fotografía por unas nociones comunes a las dos disciplinas. La sociología en la fotografía estructura lo que se podría denominar el ojo sociológico, es decir, una perspectiva social en la fotografía como instrumento de análisis, como industria, como profesión y como constructora de la realidad social. Se dice que "ver es leer» y que "una imagen vale mil palabras». La cámara ve más que el ojo humano, o al menos de forma diferente. Para su análisis se propone un planteamiento más analítico que histórico. Pero es importante introducir al principio los textos o manuales básicos (internacionales) de historia de la fotografía y de técnica fotográfica. Estos son especialmente importantes, no tanto por el repertorio de temas, la explicación de las líneas de progreso, sino también por el establecimiento del canon. Toda esa introducción sirve para estructurar los temas que se consideran básicos en la sociología de la fotografía; y que detallamos a continuación.

\section{ESCRITURA CON LUZ}

Es importante reconocer desde el principio la fascinación e ingenuidad de la imagen fotográfica, la verdadera escritura con luz (que es lo que significa "fotografía»). Se basa en lo que en el argot profesional se denomina el instante eternizado, o el momento decisivo, que es irrepetible. Se trata de un documento valioso de lo que ha ocurrido, del pasado. Es importante diferenciar los conceptos básicos de fotografía, foto, y fotógrafo/a. Un proceso histórico rápido va desde la cámara oscura a la foto instantánea y de ahí a la fotografía computerizada. La historia de la fotografía en el mundo es única en el sentido de que aparece en Europa y establece un proceso lógico de desarrollo, dominado fundamentalmente por el capitalismo y por el mundo llamado "occidental». Pero la aceptación de esta historia debe ser crítica, como debatible es la definición del canon. La historia contemporánea de la fotografía se convierte a veces en una crónica estadounidense que conviene completar y criticar.

La versión dominante es la de Beaumont Newhall, a partir de Photography 1839-1937 (en 1937), luego como director del MoMA (1940-1962). El MoMA o Museum of Modern Art (Museo de Arte Contemporáneo) en Nueva York es la institución legitimadora más importante en el mundo de la fotogra- 
fía contemporánea. Pero conviene poner en relación además las otras artes con la fotografía, como se realiza en el libro de Aaron Scharf. Una línea de investigación inicial importante es la fotografía de paisajes en que destacan algunos números de la famosa revista Aperture (desde 1952). La historia de la fotografía se puede ver, a saltos, en el trabajo realizado por el Department of Photography del MoMA en períodos de veinte años: la revisión de Walker Evans, en 1938; la colección crítica The Americans de Robert Frank, en 1958, y los veinte años editados por John Szarkowski (director desde 1962), en 1978. Es interesante realizar una comparación con la retrospectiva de Garry Winogrand, en 1988. Esa historia oficial de la fotografía desde América debe ponerse en comparación con la tradición europea de fotografía a veces más doméstica y radical. Los debates importantes ya desde el inicio son la polémica del color versus blanco y negro; de la belleza versus la realidad; la ilusión de la neutralidad; la polémica de la polisemia, así como la idea de que existen al mismo tiempo buenos fotógrafos/as que son malos filósofos/as y peores reformadores sociales.

La Fotografía es, pues, vista desde la Sociología como un fenómeno mundial. No podría ser de otra manera. Sin embargo, para el caso español conviene poner una atención especial en sus peculiaridades. Hay varias historias de la fotografía española (Lee Fontanella, Publio López Mondéjar, Manuel Falces, Carlos Cánovas) aunque ninguna de ellas definitiva, ni tampoco excelentes. La más reciente es la Historia de la Fotografía en España, de $1997^{18}$. Existe una versión de las Españas de José Ortiz Echagüe, pictoralista y conservadora, que hay que entenderla en su época y objetivo. La revista Arte Fotográfico (1952-) juega un papel importante en los años cincuenta, durante el franquismo. La rebelión del grupo AFAL a partir de 1956 debe ser tenida en cuenta. Los años setenta presencian el desarrollo de la revista Nueva Lente, 1971-1983 (de cuyo estudio trata la tesis de Enric Mira). Hay que tener en cuenta también la crítica surrealista de la sociedad conservadora que en España tiene una importancia especial. Para todo este estudio vale la revisión de los fondos de la Biblioteca Nacional, o bien la exposición del Círculo de Bellas Artes de 1983. Otro resumen global aparece en la coetánea de los 20 fotógrafos de Idas y Caos (hasta 1940), en 1984. En fotografía (en el MoMA igual, por supuesto) las exposiciones van seguidas de libros o catálogos con una influencia e impacto duradero. Hay que tener en cuenta la creación de la agencia Cover, en 1980, y la revista Photovisión (1981-). El Primer Congreso de Historia de la Fotografía Española se realiza en Sevilla en 1986, con la Revista de Historia de la Fotografía Española. La exposición del Center for Creative Photography sobre fotografía estadounidense, en Barcelona y Madrid, en 1991, tiene un impacto considerable. Aparecen las primeras biografías de fotógrafos/as españoles (como la de Alfonso). Un primer curso ya más abierto de fotografía y sociedad es el de "La Mira-

18 Publio López MondéjAR, Historia de la Fotografía en España (Barcelona: Lunwerg Editores, 1997), 303 pp. Se inicia precisamente en 1939 y se divide en tres partes: siglo XIX, 19001939, y el período de postguerra hasta 1993. 
da del Siglo XX», en El Escorial, en el verano de 1991, organizado por la Universidad Complutense, el cual marca un hito en la fotografía española. La exposición Cuatro Direcciones: Fotografía Contemporánea Española, 1970-1990, en el Centro de Arte Reina Sofía, en el otoño de 1991 es también parte del interés que se desarrolla por fin en la última década del siglo XX.

\section{CONSTRUCCIÓN SOCIAL DE LA FOTOGRAFÍA}

Se desarrolla a nivel mundial la polémica de las ventanas y los espejos. Aparecen las primeras interpretaciones filosóficas de la fotografía. Contemporáneamente se reconoce el análisis de la realidad social "sin saberlo" de algunos de los primeros fotógrafos/as. La fotografía francesa - con interés humano- de la vida cotidiana tiene un impacto duradero. Se desarrolla una teoría simple de los "momentos decisivos» (Henri Cartier-Bresson, en Images à la sauvette, 1952) y de lo que se denomina el "petit bonheur» o las visiones amables e irónicas (pero sencillas, de felicidad cotidiana) de la Europa de la postguerra, proverbialmente en Francia. Pero esta tendencia o visión acaramelada recibe algunas críticas, especialmente de las nuevas teorías fotográficas críticas, como las del tándem John Berger y Jean Mohr. Berger continúa luego dedicado a la literatura (novelística) y ensayo.

Las interpretaciones sociológicas de la fotografía son decisivas en esta época, aunque no son muy numerosas. Tienen impacto las de Gisèle Freund entre la fotografía y la sociología; la de Susan Sontag, sobre la fotografía; la de Roland Barthes y su cámara clara; muy básica la de Erving Goffman y el sexo de los ángeles; la de Howard S. Becker, con los mundos del arte, y la cámara de Jean Baudrillard que sigue, entre otros/as. Es importante tener en cuenta en el caso español la organización técnica de la realidad tras los traumas del fascismo y de la guerra civil española. La contribución de los/as españoles a estas polémicas y teorías es nula. Apenas si se leen estos libros, no se enseñan en la universidad, tampoco se debaten. No hay todavía estudios de Sociología Visual.

\section{TRABAJO DE CAMPO ANTROPOLÓGICO}

La fotografía ha sido siempre un instrumento o herramienta legítimo en Antropología ${ }^{19}$. Pero existen críticas como la del colonialismo fotográfico. Se observa la institucionalización de la antropología visual como disciplina, e incluso como título universitario en algunos casos (especialmente en Estados Unidos). La fotografía pasa a ser, en manos de antropólogos/as, un método de investigación legítimo y cada vez más prestigiado. Se puede ver su uso clásico

19 Uno de los textos más recientes es Marcus Banks y Howard Morphy (eds.), Rethinking Visual Athropology (New Haven: Yale University Press, 1997), 306 pp. 
en Los Nuer. Se utiliza mucho en los análisis de vida del campesinado. También en los estudios del folclore. Los «tipos y trajes» de la España de José Ortiz Echagüe (1930) es un ejemplo desencajado de esta función de la fotografía. Este movimiento lleva a la fotografía la visión de salvajes, indios y paletos, a veces con graves inexactitudes. Todavía tiene influencia el proyecto en cuarenta tomos de The North American Indian, de Edward S. Curtis (1907-1930), a pesar de la falsedad manifiesta de algunas de esas fotos, que tratan de rescatar un pasado que ya no existe cuando las fotos se realizan, pero que corresponde a sus antepasados. Se produce así una doble búsqueda (fotográfica) de las raíces del pueblo indio en Norteamérica. Es quizá más interesante las cartas y fotos del trabajo de campo de Margaret Mead; y sobre todo su estudio fotográfico sobre la infancia en Bali.

La Andalucía de Stanley Brandes no tiene un contenido fotográfico, pero complementa las visiones fotográficas folclóricas andaluzas (a menudo por extranjeros/as) que se producen paralelamente a ese estudio. El método biográfico y las historias de vida - por ejemplo, el manual de Juan J. Pujadas_ es otra forma de ilustrar las relaciones de texto y foto, realizadas por autores diferentes, sin conexión, pero que suceden al mismo tiempo ${ }^{20}$. El estudio del emigrante en Hacer la América, de Juan F. Marsal, la historia de un minutero (un fotógrafo ambulante), es decisiva en el análisis sociológico cualitativo en España. Se siguen haciendo fotos de fiestas: la Patum de Berga, según Jaume Farràs, es un ejemplo excelente. La España oculta, de Cristina García Rodero, es un proyecto más estético y ambicioso, pero le falta un análisis serio. Los temas de la «España negra» reaparecen constantemente, así como la España del toro frente a la España del caballo, presente ya en Picasso. Llama la atención las fotos para Médicos Sin Fronteras, de Sebastião Salgado, que tiene un impacto considerable en el mundo latino, primero, y luego en el internacional.

\section{COMO MÉTODO DE INVESTIGACIÓN SOCIOLÓGICA}

La visión teórica reconoce que la Fotografía puede ser una parte de la Sociología, no necesariamente complementaria, sino como forma autónoma de producir teoría y de avanzar el conocimiento. En sus inicios está ya la fotografía de documentos sociales, como denunciadora de problemas sociales (pobreza, marginación, industrialismo, construcción de rascacielos, racismo, infancia abandonada, trabajo infantil, crimen, enfermedad, etc.). Se debe desarrollar una distinción inicial entre escenario público y privado. Las ciencias sociales

20 Sobre el método biográfico conviene ver en español, al menos: Juan J. PUJADAS, El método biográfico: El uso de las historias de vida en ciencias sociales (Madrid: Cuadernos Metodológicos, Centro de Investigaciones Sociológicas, 1992), 107 pp.; y Jesús M. DE Miguel, Auto/biografías (Madrid: Cuadernos Metodológicos, Centro de Investigaciones Sociológicas, 1996), 197 pp. Un estudio aplicado es el de Omar G. PONCE DE LEÓN, El médico enfermo: Análisis sociológico del conflicto de roles (Madrid: Centro de Investigaciones Sociológicas, 1997), 326 pp. 
apoyan el realismo y la técnica del f/64 que pretende un realismo considerable y una nitidez de las situaciones sociales. Desde una perspectiva reformadora se apoya y se desarrolla la teoría de la dignidad humana y la convivencialidad. Desde una perspectiva conservadora se defiende la unicidad de la naturaleza humana y la importancia de la familia en proyectos como The Family of Man (Edward Steichen), en 1955, de enorme alcance en la historia de la fotografía. Hay muchos otros proyectos sobre la condición humana. Está la idea del ensayo fotográfico (por ejemplo, en William A. Allard). Una contribución sociológica clave es la de los doce proyectos fotográfico-sociológicos de Exploring Society Photographically, editados por Howard S. Becker, quizá una de las contribuciones sociológicas más importantes a la fotografía. Pierre Bourdieu et al., presentan casi por sorpresa (sin un interés previo de los sociólogos franceses) el manual $U n$ art moyen: Essai sur les usages sociaux de la photographie. Bourdieu vuelve a la carga en un estudio más reciente sobre la televisión en 1996, que levanta una cierta polémica. En la sociología teórica es parte del análisis del contexto social (básicamente, Framework Analysis, de Erving Goffman). Se pasa así del voyeurismo y la fascinación al conocimiento de la realidad social en proyectos importantes como: Circus Days, The Bikeriders, Suburbia, City Families, East 100th Street. Las experiencias de John Berger con Jean Mohr no encaja dentro de esta tendencia, ya que ser más europea y crítica. De la misma forma se producen visiones radicales como las británicas; la más significativa, la de Jo Spence.

\section{LA HISTORIA EN FOTOS AMARILLAS}

La fotografía es un instrumento esencial para el análisis de la Historia, sobre todo de la historia más social. Un problema sociológico interesante son las fotos que se desvanecieron, las que se destruyen o desaparecen o las que se amarillean. Se pueden diferenciar cuatro contribuciones históricas de la fotografía: la de la nueva sociedad ideal (que se está haciendo), la sociedad oculta, la sociedad que desaparece y la sociedad que no se acepta como es. A la sociología le interesa diferenciar - y desarrollar- las cuatro. El proceso obvio en relación a la imagen es el paso de las artes a la fotografía. Es importante el intento de reconstrucción de la historia a partir de las fotos del inicio de la fotografía. Entre los clásicos a conocer mejor está Nadar. También están los testimonios de la destrucción (o construcción) arquitectónica, sobre todo de la gran ciudad, que es la que se crea en el siglo XX. La fotografía sirve para la historia de instituciones; como la del Hotel de Londres y de Inglaterra, en San Sebastián, por poner un ejemplo local interesante, testigo de una época y estilo de vivir. Se pone de moda cada vez más el estudio y teorización de la sociedad oculta... para el fotógrafo/a. Se fotografía la vida nocturna de las ciudades, barrios periféricos, entramado urbano que no son monumentos. Se evidencia a través de exposiciones el proceso de dignificación de las fotos con el paso del tiempo. 
La fotografía se descentraliza y aparecen numerosas recolecciones de pueblos y regiones. Así, por ejemplo, las ferias y mercados de Huesca; los habitantes de Trujillo en La memoria quieta; el Albacete que aparece en los Retratos de la vida con las fotos de Luis Escobar; el caso de Cantabria; las recolecciones de Publio López Mondéjar en Crónica de la luz (1984) y Las fuentes de la memoria (1989). Se canonizan —en el sentido de que se incluyen en el canon- por vez primera los fotógrafos de pueblo (como Tomàs Montserrat). Se produce la polémica de las fotos mudas sin contexto. También se pone en cuestión el desarrollo primitivo de las expediciones fotográficas. Se evidencia una urgencia por fotografiar un mundo en trance de desaparecer; es el caso de los/as últimos trabajadores industriales, en Richard Avedon o en Sebastião Salgado. La fotografía se utiliza también como forma de aprender: las cosas ya no son como antes.

\section{LA FOTO ANÓNIMA}

Fotógrafos son las personas que se denominan fotógrafos a sí mismos. Pero hay muchos más fotógrafos (anónimos) en la historia de este siglo XX. Es posible desarrollar una Sociología visual de la vida cotidiana en base a la fotografía doméstica producida anónimamente, que tampoco pretende presentarse a concursos, ni ser considerada artística. Es la fotografía que sirve para definir las historias familiares particulares y la evolución de familias concretas. Existe una doble relación foto/vida social. Gradualmente es cada vez más importante la utilización doméstica y simbólica de la foto. Es clave para este estudio la exposición sobre Pleasures and Terrors of Domestic Comfort, en el MoMA, en noviembre 1991. Los sociólogos/as desarrollan varios proyectos interiores, estudios fotográficos de la vida familiar o de la forma de vivir en el hogar.

No se han analizado hasta ahora los álbumes familiares pero puede ser una fuente sociológica importante de conocimiento de la realidad social ${ }^{21}$. Se producen de forma masiva instantáneas de los ritos de paso: nacimiento, bautizo, comunión, orla escolar, boda, fiestas, viajes y muerte ${ }^{22}$. Algunas relaciones importantes entre foto y pintura se puede ver en una tradición latinoamericana (sobre todo mexicana) en Frida Kahlo, entre otros muchos autores. Esto se combina con el uso del retrato y autorretrato. Un tema curioso es el de la sonrisa en la fotografía - la costumbre del «di luisss» o del «say cheese» que es un tema relacionado con las pautas de migración. Se desarrollan además teorías sobre la foto cándida, que se relacionan con la producción televisiva de «objetivo indiscreto" (candid camera, en Estados Unidos), posteriormente "vídeos de primera», y tantos otros remakes.

${ }^{21}$ Como lo pueden ser las cartas o correspondencia (incluyendo las cartas de amor).

22 Es importante la discusión teórica de la fotografía en la muerte, que cambia con las décadas. Las fotos de los recién nacidos (antes tan importantes) desaparecen, en parte con la bajada de la natalidad (y mortalidad) y sobre todo con la secularización: ya no son «angelitos» que van al cielo. La idea aparece en Blanco White. 
Hay una utilización importante en la primera mitad del siglo de las cartesde-visite. Un tema diferente pero relacionado es el de las tarjetas postales, que navega entre el hiperrealismo y la nostalgia cristalizada. En la historia de la fotografía algunas de esas "postales», especialmente las de grupos étnicos, son descaradamente pornográficas. Durante unos años estuvo muy de moda el sistema en relieve de dos fotos paralelas, tanto para monumentos o lugares exóticos, como para foto pornográfica. Más perdurable son los avances posteriores de popularización: el color, instamátic, polaroid, photomatón. Están también los inventos de kodak, leica, polaroid desde la perspectiva de la industria. Todos esos avances tienen efectos perdurables sobre la producción fotográfica mundial. Las dos polémicas más interesantes (no resueltas aún) son: las fotos que desaparecen y los fotógrafos/as olvidados.

\section{ESTUDIO DE COMUNIDADES}

Un objetivo importante es la utilización de la fotografía para el análisis de comunidades enteras: pueblos, ciudades, incluso países. Inicialmente se parte de una concepción de la fotografía como metáfora - desde las excelentes contribuciones de Ansel Adams y Minor White- en que se fotografían objetos y sujetos con significados simbólicos: vallas, nubes, escaleras, manos, perros. Algunos de estos motivos (como las escaleras) aparecen repetidamente en la fotografía posterior, incluso de forma inconsciente. Esos temas se conservan como tópicos recurrentes en la fotografía internacional. Es proverbial, por ejemplo, la importancia de los parques nacionales, como el de Yosemite, desde los años veinte. Están también los «equivalentes» de Alfred Stieglitz y las fotos de nubes que es un motivo peculiar. Es muy personal la obra de Edward Weston, incluyendo una dramatización de la naturaleza, del desnudo, de objetos; todo ello con un significado social comprometido. Años más tarde se produce una crítica de la «inocente» fotografía de paisajes, por ejemplo, en Aperture (desde 1952) y su Beyond Wilderness (de 1990). Una línea diferente pero conectada es la de la fotografía desde el aire. Pero la metáfora de la sociedad, o de la realidad, da paso a la fotografía de la sociedad en acción.

El primer gran clásico son las 38/100 fotos de How the Other Half Lives, de Jacob A. Riis, en 1890. Es un análisis sociológico-fotográfico muy temprano pero apenas superado, y que se convierte en un clásico importante. En una misma línea de importancia está el análisis del carácter nacional en The Americans de Robert Frank, o en la India de Henri Cartier-Bresson. Son portafolios clásicos, "de culto" como se diría en cine. La importancia de la serie de los/as americanos de Frank es central en la profesión. Existen otros proyectos sobre las grandes ciudades, en donde sobresale el rol central de Nueva York y París en la fotografía. Va desde los edificios y calles de Eugène Atget al París nocturno y secreto de Brassaï (1931-1939). Es importante también la serie de ciudades británicas del Picture Post, en 1938-1939, de Humphrey Spender. El 
Nueva York nevado de Alfred Stieglitz, los rascacielos de Berenice Abbott, y el Nueva York, conflictivo y a menudo delincuente, de Weegee, son momentos importantes del análisis de comunidades, que se convierten en canon rápidamente. En España hay fotógrafos/as de comunidades como Tomás Montserrat, en Llucmajor (Mallorca), y sus fotos de 1900-1925.

En América, siguiendo las ideas de la Escuela de Chicago, se produce un análisis de comunidades pequeñas: Middleton (Muncie, en Indiana, en realidad), en 1929 y en 1935, por Robert y Helen Lynd; y en You Have Seen Their Faces, en 1937, de Margaret Bourke-White. El otro proyecto clave es el de Let Us Now Praise Famous Men, del verano de 1936, realizado por Walker Evans y James Agee, finalmente publicado en 1941. Está también el proyecto de la Farm Security Administration, y las fotografías de Walker Evans y de Dorothea Lange en torno a la Gran Depresión.

Se realizan estudios sobre los pequeños dramas urbanos de la vida cotidiana por fotógrafos establecidos como Brassaï, Robert Doisneau, Henri CartierBresson, André Kertész, David Seymour, Elliott Erwitt y Manuel Álvarez Bravo. Hay otros proyectos urbanos más concretos pero de excelencia como el de East 100th Street, el Spanish Harlem, según Bruce Davidson; la Suburbia, de Bill Owens (1973); Main Street en Estados Unidos, o la Avenida Diagonal en Barcelona. Un campo paralelo menor es el de los libros turísticos y sus modalidades (como los publicados en España sobre Guipúzcoa, Murcia, Cuenca y muchísimos otros).

\section{ANÁLISIS DE DESIGUALDADES SOCIALES}

El centro de la Sociología es el análisis de la estructura y los procesos de desigualdad social. Es importante la posible aplicación de la Fotografía a ese campo de estudio. Es posible realizar un análisis de la explotación humana mediante fotografías. Una contribución ya clásica es el proyecto sobre tipos sociales en Alemania en "El hombre del siglo XX", de August Sander, y en Antlitz der Zeit (1929). Hay una versión de los tipos humanos del Oeste (americano), de Richard Avedon, en 1985. También es importante el análisis de las diferencias por género en Gender Advertisements, de Erving Goffman. Hay bastantes estudios de personas ancianas como el de Imogen Cunningham, en After Ninety, y son importantes las series de Nicholas Nixon. La lucha por los derechos civiles de los negros/as en Estados Unidos es un tema bastante fotografiado, al igual que los/as inmigrantes en cuarentena en la Isla Ellis (1904-1909). Inmigrantes, trabajadores y niños/as trabajando son los temas centrales de los estudios del sociólogo/fotógrafo Lewis W. Hine que marca un estilo ya definitivo en estas corrientes fotográficas.

La Sociología utilizando Fotografía se dedica también a las personas en los márgenes de la sociedad «normal». Así está, entre otros muchos, el proyecto Ladies. Los gitanos/as es un tema importante, pero en algunos casos con aten- 
ción a las gitanas, como en un excelente trabajo sobre las del Camp de la Bota. Otros grupos minoritarios analizados son: étnicos (judíos/as, gitanos/as, africanos/as), viejos/as, locos, locas, prisioneros/as, prostitutas, personajes callejeros, etc. La fotografía se entiende a veces como instrumento de lucha social y de propaganda política. Sobresalen también los proyectos sobre la dignidad (sin mérito) de ser pobre o marginado/a desde los ya clásicos durante la depresión económica en Estados Unidos. A veces se producen análisis de marginación doble (como pobreza-e-infancia). Es importante tener en cuenta la polémica de la romantización, sobre-esteticismo, de la pobreza y la desigualdad social. En el otro extremo están los portafolios sobre los nuevos ricos/as (en Gran Bretaña: el proyecto de Martin Parr). La "fotografía feminista» ocupa un lugar central en el análisis de las desigualdades sociales: Tina Modotti, Jo Spence, Barceldones, el estudio británico de Val Williams, 1840-1986, entre otros, son representativos. La fotografía feminista, o al menos realizada por mujeres, supone un punto de vista generalmente diferente, aunque no trate necesariamente el mundo de la condición femenina.

\section{NUEVOS ESTUDIOS DE LA REALIDAD SOCIAL}

En los últimos años se observa una considerable inventiva en los proyectos fotográficos aplicados a la realidad social. Aparecen estudios y análisis que conviene reseñar y estudiar. Algunos son novedosos por los temas, otros por la técnica, otros por el proceso de realización o de presentación; pero todos son interesantes. Se refieren a un planteamiento de "temas» sociales concretos, en proyectos y portafolios de características diferentes a los años anteriores. Un tema novedoso es el de qué pasó con las personas en la foto, que se denomina "refotografía». Se produce así, también, una vuelta a los pueblos y a las personas fotografiadas — por ejemplo, durante la Gran Depresión- por la Farm Security Administration, pero varias décadas después. Hay también los estudios de paradojas y contraposiciones, que tienen una tradición más clara, pero con nuevas técnicas y temas. Están la serie de los Laughing Camera. Se producen también bestiarios. Un tema nuevamente enfocado es el de enfermos/as terminales ante su muerte. Es interesante también la cámara que sigue, por ejemplo, la de Sophie Calle, analizada por Jean Baudrillard. Es cada vez más importante la incursión psicoanalítica en la terapia fotográfica o fototerapia.

Más clásicas, pero con nuevas ideas, están las iconografías personales o el uso de biografías fotográficas como las de Buñuel (cineasta) o Rivera (pintor muralista). Los diarios de fotógrafos son una nueva fuente de inspiración y teorización como los Daybooks, de Edward Weston (1922-1934). Se multiplican las biografías y autobiografías de fotógrafos/as. Entre las más importantes se pueden comparar la de Ansel Adams, en 1985, con la de Don McCullin, en 1990, o la más reciente de Robert Mapplethorpe. Se produce una búsqueda de las raíces familiares o autobiográficas mediante fotos. Reaparece la fotografía 
como control social y policíaco, con nuevas técnicas y quizá menos dedicación periodística. Un proceso novedoso es el del análisis radical, sobre todo con la obra emblemática de Jo Spence. Se analizan las otras profesiones dobles: escritor-fotógrafo (Juan Rulfo), modisto-fotógrafo (Karl Lagerfeld), revolucionariafotógrafa (Tina Modotti). También está la mezcla de fotografía y poesía. Una nueva línea de investigación es lo infotografiable (música, oscuridad, movimiento, sentimientos, poder) como fotos invisibles. En los últimos años se fotografían los temas prohibidos, tabú. Se produce una nueva fotografía del cuerpo, incorporando el feísmo.

\section{PROYECTOS DE CAMBIO SOCIAL Y POLÍTICO}

¿Cómo se cambia la realidad social con fotos? Es una buena pregunta que tanto la Sociología como la Fotografía no sabe contestar todavía. No se trata sólo de denunciar, sino de realizar un análisis crítico, serio y profundo de una realidad social concreta. Se critica así el espejismo del cambio o de la radicalidad en la llamada fotografía concerned. Hay toda una "nueva fotografía» (tras la primera Guerra Mundial) del nuevo orden social: Alexander Rodchenko, Man Ray, Lászlò Moholy-Nagy. Se reconoce que la fotografía puede servir como inspiración de «las masas» para la acción. También está el proyecto Photography/Politics en Gran Bretaña.

Se producen análisis de grandes procesos de cambio social: urbanización, industrialización, maquinismo, construcción de obras (como el Museo Guggenheim, en Nueva York o en Bilbao), o de rascacielos (como el emblemático Empire State Building, por Lewis W. Hine). Durante una época se observa una cierta tendencia a fotografiar la supuesta belleza de las máquinas, desde Paul Strand (1922) hasta la crítica cinematográfica de Chaplin en Tiempos Modernos. Igualmente atraen las grandes ciudades (el caso de Nueva York). La fotografía navega entre la propaganda y el cambio de la realidad; así, por ejemplo, en el análisis de la Gran Depresión en el caso de Roy E. Stryker, la Farm Security Administration, y el Proyecto América de Walker Evans. Están también los montajes patrióticos del MoMA, en 1942-1945 (Edward Steichen, Road to Victory), actualmente algo olvidados por sus connotaciones pero que merece la pena estudiar. La agencia Magnum (1947-) y sus visiones es esencial, aunque haya tenido más atención de la que seguramente merece para un análisis social riguroso; así, sus estudios sobre China, las guerras o la música. En este campo es importante The International Fund For Concerned Photography, Inc., y las series de estudios-libros titulados The Concerned Photographer. Mayo del 68 atrae una buena cantidad de fotografías y fotógrafos/as de la que todavía no se ha producido un análisis adecuado. En cambio, el movimiento de derechos civiles (civil rights movement) sí recibe una atención fotográfica más elaborada o estructurada. La fotografía de guerra es una especialidad reconocida: desde la Guerra de Crimea (1855), las experiencias de la guerra civil norteamericana 
(1861-1965), y las dos guerras mundiales. Están los fotógrafos de las guerras contemporáneas, como Robert Capa (muerto fotografiando en Indochina, en 1954), David Seymour (muere en Suez, en 1956), W. Eugene Smith, Donald McCullin, David Douglas Duncan. Las guerras que más atraen la atención —en primer lugar, la guerra civil española de 1936-1939— son las de Vietnam, China, el Golfo, Moscú, Bosnia. El caso de la guerra civil española es central para el análisis de la fotografía comprometida y la fotografía de guerra. En tiempos de paz están los estudios similares en el caso de los derechos civiles de los negros/as, como el de Charles Moore.

Los fotomontajes o la utilización de la fotografía para la realización de pósters con intención política es importante desde los primeros fotomontajes antinazis de John Heartfield, en los años treinta. Están también los fotomontajes de Salvador Dalí, pero sobre todo la obra del valenciano Josep Renau (1967), cada vez más de moda. Hay que tener también en cuenta la idea de fotomontajes como contra-anuncios. El sida es una epidemia-enfermedad que impulsa numerosos estudios de fotografía de diverso tipo. Está así la visión gráfica del sida (Act Up) y del movimiento gay. La foto es también importante en libros de educación sexual como $; A$ ver! Los libros pro-vida o anti-aborto utilizan profusamente la fotografía como proyecto de cambio (o incluso reacción) socio-político. Con objetivos similares, pero ideológicamente distintos, está la fotografía para la defensa del medio ambiente y de las especies animales.

\section{LA FOTO COMO NOTICIA E INFORMACIÓN}

La revolución de la fotografía en imprenta supuso un cambio importante. La fotografía se utiliza profusamente en los medios de comunicación que se dedican a noticias e información, lo que se entiende por fotoperiodismo. El mensaje es el medio de la prensa. Se produce una especialización en las fotos de desastres, accidentes, sucesos, violencia. Se observa además un auge de los fotomagazines y del papel de las revistas. Los estudios ya clásicos incluyen a W. Eugene Smith con sus reportajes fotográficos en la revista Life sobre el "Country doctor", "Life in a Spanish Village» (1948-1951) y el proyecto Minamata. Hay reportajes importantes en las revistas Vu (1928), Life (19361972) y Look (1937-1971). El caso más especial es el de la revista Life y el Life Classic Photographs (por ejemplo, la selección realizada por John Loengard). Es llamativa la supervivencia peculiar del National Geographic. Están también la fundación World Press Photo Holland (desde 1955) y el anuario World Press Photo.

Existe una relación creciente entre fotografía, prensa escrita, prensa del corazón y televisión. Son también importantes los procesos de informatización de la imagen. El papel de los (las) paparazzi es un debate continuo en los finales del siglo XX, sobre todo tras la muerte de Diana Spencer, princesa de Gales, en París, en el verano de 1997. En España está la recopilación Flash: Un año en 
la vida de España y la historia española de medio de siglo en Efemérides (19391989) de la agencia EFE, y los libros que se siguen publicando en torno a estos ficheros de fotos. Son conocidos y populares los reportajes del Blanco y Negro (desde 1891). Las «revistas de corazón» con la vida de la clase alta (¡Hola!, Semana, Panorama), y los reportajes sobre la sociedad marginal (El Caso, Inter$v i u$ ) centran la atención fotográfica. El periodismo amarillo, todavía en auge, utiliza profusamente la fotografía. Hay que reconocer el rol innovador de $E l$ País en fotografía, derechos de autor/a, y el tratamiento periodístico de las fotos.

\section{MERCADO Y ORGANIZACIÓN DE LA FOTOGRAFÍA}

La Sociología Visual analiza también la industria fotográfica y el mercado de la fotografía. La fotografía es un sector productivo importante. Esto apenas si se ha analizado. Los actores en este sector son varios: fotógrafos/as, laboratorios, merchantes, agencias, museos, fundaciones, publicidad, revistas, periódicos, creadores y transmisores de imágenes, industria químico-fotográfica, productores de cámaras, nuevas tecnologías, ordenadores que fotografían y que procesan fotos, etc. Habría que partir del estudio de los antiguos retratistas y minuteros. Está la obra de Nadar y de Julia M. Cameron. Se trataría luego de analizar la fotografía versus la televisión o el cine. Está el caso curioso de las fotos de Le Monde. La profesión de fotógrafo/a es un tema obvio de investigación. Otros temas importantes son la influencia del fotoperiodismo, documental, televisión, y el fotógrafo/a amateur. Existen todo tipo de conflictos y de luchas gremiales y por el copyright. Hay que analizar las normas, los cánones, las reglas profesionales (escritas e informales), los manuales de estilo.

Otro tema son los clubes clásicos: Photo-Club de París, el Linked Ring (1892-1910) en Gran Bretaña. Es clara la importancia de la industria: sobre todo la Eastman Kodak Company. La compañía alemana Leica tiene un rol especial. Hay que estudiar también las distintas escuelas: impacto de la Bauhaus, Group f/64 en 1932-35 (con la influencia de Edward Weston), Photo-Secession y las Little Galleries ( «291») en 1902-1917, Alfred Stieglitz y los cincuenta números míticos de Camera Work (1903-1917), Magnum Photo (1947-), etc. Las otras agencias, como Gamma, son también importantes de tener en cuenta. Todo el tema de exposiciones y galerías (fotográficas y no tan especializadas) se basan en la idea de las fotos para ser vistas colgadas en la pared. Es clave el papel de los museos - y sus exposiciones - sobre todo en la institucionalización y legitimación de la fotografía. El MoMA, desde 1940, es la institución más importante y legitimadora, definidora además del canon fotográfico. Conviene estudiar cómo ha ido evolucionando. Hay museos dedicados al tema como el de Amberes, la exposición permanente del MoMA, el International Museum of Photography en la George Eastman House (en Rochester, en el estado de Nueva York, desde 1949). Existe además toda una serie de anuarios fotográficos. Están 
los premios a fotógrafos/as, de todo tipo y nivel, cada vez más usuales en el mundo. Los libros de fotos suponen una forma de seguir manteniendo el control del autor/a. Además están los libros objeto y los libros-regalo.

Conviene analizar las fototecas y los bancos de fotos. El Center For Creative Photography (University of Arizona, Tucson) es uno de los centros más innovadores e interesantes. Está además el Centre National de la Photographie (París) y las exposiciones clave del Centre Pompidou. Está también la Photokina anual desde 1950 (en Colonia). La foto en la publicidad es un tema importante, con el papel dinamizador de Vogue (Les Publications Condé Nast SA), y Vanity Fair. En la misma línea están los retratos elegantes de Irving Penn o los de Richard Avedon. En España se observa una tendencia similar (pero menos interesante) con las fotografías de Alberto Schommer. Son bastante más originales y llamativos los retratos «anormales» de Diane Arbus, una de las fotógrafas más decisivas en los cambios producidos en la fotografía contemporánea.

Un tema teórico interesante es del desnudo legítimo. Relacionado con ello está la utilización de la fotografía para las fantasías (sobre todo) masculinas. La fotografía es básica en la pornografía fotográfica: blanda y dura. Está el fenómeno Playboy y sus playmates que marcan una tendencia determinada. La polémica sobre The Black Book, de Robert Mapplethorpe, y de toda su obra es central para entender unas tendencias concretas: gay y SM. Un desarrollo algo diferente son los estudios de ninfas de Hamilton.

Las revistas de fotografía en España tienen importancia y merecen un análisis detallado: Arte Fotográfico, Cinema 2002, Eikonos, El Progreso Fotográfico, Flash Foto, Foto Profesional, Ikuspen Comunicación Visual, Imagen y Sonido, La Fotografía, Nueva Imagen, Nueva Lente, Photo, PhotoVisión, Revista de Historia de la Fotografía Española. La enseñanza de la fotografía en la Universidad española está subdesarrollada, relegada normalmente a Bellas Artes, y con poco entusiasmo. No hay prácticamente análisis sociales de la fotografía, del mismo modo que la fotografía no se utiliza en España para el análisis de la realidad social. Quizá la situación cambie en el siglo XXI.

\section{FOTOGRAFÍA Y MOVIMIENTO}

Paradójicamente la fotografía fija — la conocida como still photographypuede verse en secuencias, en movimiento, como un paso previo o lateral al vídeo, televisión, cine. Se trata, pues, de la acción paralizada o congelada. La polémica empezó con el caballo "Occident», de Stanford (en 1873), cuando la cámara ve más que el ojo: se descubre que en un momento del galope los caballos tienen las cuatro patas en el aire ${ }^{23}$. La obra fotográfica clásica es la de Ead-

${ }^{23}$ Inevitablemente, el tema de discusión recuerda las patas de los caballos corregidas de varios de los cuadros de Velázquez. 
weard Muybridge. Posteriormente aparecen los múltiples, y las fotosecuencias, no necesariamente como pasos previos al cine, sino como alternativas, o como formas de investigar y teorizar. La obra de Duane Michals es importante. Un aspecto más elaborado es el documental y cine-documental. Se utilizan cada vez más las fotosecuencias, a menudo con audiovisual. Entre las obras más importantes, ya clásicas, están las series temporales de Nicholas Nixon: las hermanas Brown (durante trece años sucesivos) y el enfermo de sida (12 fotos). En la misma línea está el proyecto People With Aids.

Estas experiencias se acumulan a los fotorreportajes más clásicos. Un tema polémico es la progresiva decadencia de los foto reportajes, o incluso su desaparición como género, debido a la invasión de la televisión con la que difícilmente puede competir. Hay un cine más fotográfico del usual y también más de culto, como "El perro andaluz», «Viridiana», «Bienvenido Míster Marshall», «El gallo de oro»y, desde luego, «Rashoomon». Esta última película —de Akiro Kurosawa, de 1950 - merece una reescritura sociológica. Está, además, el famoso Viaje a las Hurdes. Un libro básico es el Heart of Spain, editado por Paul Strand, al que hay que sumar The Spanish Earth, de 1937, por Joris Ivens. Una discusión teórica de teatro/cine/foto aparece en el libro Linterna mágica, de Ingmar Bergman. Habría que analizar también la foto sorpresa, sin avisar, en proyectos más interesantes de lo que parece, desde Candid Camera y Objetivo Indiscreto a Vídeos de Primera. Un tema importante es la utilización mediática de la fotografía a través de la televisión.

\section{ESPAÑA VISTA POR LOS EXTRANJEROS/AS}

Un estudio de Sociología y Fotografía en el caso de España no puede olvidar los análisis de este país realizados desde fuera, con ojo de outsider. Las visiones distorsionadas suponen una buena forma de análisis posterior. Es posible realizar un proyecto global de metanálisis con este tema. Se debe comenzar con el viaje a España de James Craig Annan en 1913. Luego está la visión del fotógrafo inglés Charles Clifford (estancia en España en 1852-1863), que se convierte en el fotógrafo oficial de la reina Isabel II; del francés J. Laurent (con su estancia en España en 1857-1875) y del danés Christian Franzen (Karlak). Es crucial el papel dinamizador de la guerra civil que atrae la atención política, intelectual y también fotográfica de todo el mundo. Así, están la obra de Robert Capa en el Ministerio de Asuntos Exteriores; las colecciones de la Biblioteca Nacional; de Chim (David Seymour) y el trabajo de la Bienal de Venecia de 1976. Es interesante entender la visión estereotipada de España: la denominada España negra, cañí, machista, pobre, religiosa. Supone una visión tradicional, de bares, procesiones, devotos, mujeres vestidas de negro, personajes bestiales, y sobre todo, corridas de toros y toreros. También está la visita fotográfica de Robert Frank a España, en 1950. 
Es importantísimo el reportaje de Spanish Village en Life (el 9 abril de 1951), de W. Eugene Smith, sobre el pueblo Deleitosa (en Cáceres) ${ }^{24}$. Conviene compararlo con las fotos del viaje a Las Hurdes, y luego el documental Tierra sin pan, de Luis Buñuel. Está también Hemingway y el tema del honor tanto en sus novelas (distorsiones de la realidad española, como el For Whom the Bell Tolls, o en Fiesta), y las fotos de Loomis Dean, en Life (1960). Están también los gitanos/as extremeños fotografiados por Irving Penn, en 1965 en la finca de la Condesa de Romanones. Hay que tener en cuenta las visiones particulares de los/as vecinos: Henri Cartier-Bresson, en 1933-1934; Brassaï (Sevilla, 1954; Picasso, 1948 y 1964), y David Seymour. Un tema recurrente es el de los grandes pintores fotografiados, sobre todo Picasso, Miró, y Dalí. Este último, Dalí, tiene un cierto interés personal en la fotografía (exposición de 1983). También hay un análisis de los vascos/as, según William A. Allard. Cataluña y Extremadura aparecen en varios reportajes en el National Geographic ("Catalonia: Spain's country within a country», "Extremadura: Cradle of conquerors»). Están, además, las obras de Sciascia y Scianna. Quizá la mejor exposición que resume estas tendencias (aunque faltan cosas importantes) es la de Europalia, en Bélgica, en 1985. El proyecto de los cien fotógrafos/as de Un día en la vida de España, el 7 de mayo de 1987, es comercial, y quizá estereotipado, pero interesante de analizar.

Un estudio de España no puede olvidar la fotografía latinoamericana, ni las relaciones estrechas, a veces, entre fotos en ambos lados del océano. Así está, por ejemplo, el histórico viaje de Walker Evans a Cuba (1933). Es llamativo el Perú de Martín Chambi. Es significativa la contribución sobre las otras Américas de Sebastiāo Salgado. Otro país visto desde fuera es México. Hay que llamar la atención sobre la fascinación de los fotógrafos/as cosmopolitas sobre México, por ejemplo, en el caso de Edward Weston y Tina Modotti, en 19231926; Paul Strand, en 1932-1935. La visión indigenista de Manuel Álvarez Bravo se incluye ya en el canon de la fotografía internacional, debido al respaldo del MoMA. Conviene analizar las relaciones fotográficas y sociales comunes entre España y Latinoamérica.

Todos estos temas establecen la agenda de la fotografía social o de la sociología fotográfica del próximo milenio. La situación de España es de un atraso manifiesto. Las posibilidades de la fotografía para avanzar el conocimiento y producir nuevas teorías dentro de las ciencias sociales, es un campo de investigación todavía por descubrir en España. Es probable que nuevas generaciones de científicos/as sociales se dediquen a esta parte de la investigación audiovisual, que es la fotografía fija, con un nuevo ojo sociológico.

${ }^{24}$ Véase el artículo de Stanley BRANDES y Jesús M. DE Miguel, "Fotoperiodismo y etnografía: El caso de W. Eugene Smith y su proyecto sobre Deleitosa», en Revista de Dialectología y Tradiciones Populares (1998). También, el libro en elaboración de Jesús M. DE Miguel, Imágenes del cambio social (1999). Un manual de Sociología Virtual es el de María Jesús Buxó y Jesús M. de Miguel (eds.), De la investigación audiovisual (Barcelona: Proyecto A, 1999). 


\section{BIBLIOGRAFÍA ESENCIAL}

La bibliografía actual en el mundo - libros, artículos, diccionarios y manuales- de Fotografía es extensa y dispersa ${ }^{25}$. No hay un corpus claro de textos (fotos) clásicos. El canon es todavía un elemento esencial de discusión en Fotografía al final del siglo Xx. Pero es una contribución etnocéntrica, en que el desarrollo gira en torno a Europa (sobre todo París y Londres) y Estados Unidos (sobre todo Nueva York). El desconocimiento internacional de otras fotografías, sobre todo las producidas en el Tercer Mundo, es llamativo. La consagración de un fotógrafo/a pasa por una exposición «internacional» - a ser posible en el $\mathrm{MoMA}^{26}$ - y la publicación de un libro de fotos por una editorial anglosajona dominante. La presente bibliografía se refiere a la fotografía fija o instantánea, y apenas puede evitar los sesgos cosmopolitas anteriormente citados.

Para un científico/a social le interesa empezar por ver/leer algo general, sobre "el arte de mirar", para lo que el librito de John Berger, Ways of Seeing, es excelente (existe una edición en español). Enseña a pensar y a mirar. No hay unanimidad respecto de lo que suponen los clásicos en fotografía, por lo que cualquier visión histórica es bastante etnocéntrica, como documenta el excelente manual de Liz Wells (1997). Un libro introductorio reciente es el de Graham Clarke, The Photograph (1997) en la colección Oxford History of Art. Más sistemática es la Historia de la fotografía, de Beaumont Newhall (publicada por Gustavo Gili, en Barcelona, 1983). Es bastante mejor (aunque más antigua) que el manual de John Szarkowski; aunque podría ser sustituido por el de Ian Jeffrey (1981). Se recomienda leer el texto de Newhall de atrás a adelante, es decir, comenzando por el último capítulo (el 16) y leer por capítulos en orden decreciente... hasta que se pierda el interés. Es importante también leer los incisivos ensayos de Susan Sontag, en Sobre la fotografía (Barcelona: Edhasa, 1981), y quizá la inolvidable historia-de-vida Hacer la América (Barcelona: Ariel, 1972), por Juan F. Marsal, que es la autobiografía de un minutero. Las personas que dominen el inglés pueden leer además algunos capítulos (los que más le interesen personalmente) de los catorce, en The Contest of Meaning, editado por Richard Bolton (MIT en 1989). Una recopilación de textos clásicos es la de Vicki Goldberg, Photography in Print (1988). Como glosario de referencia es útil tener a mano el Diccionario de la Fotografía, de Hugo Schöttle (1982), o algún otro similar.

Para las personas que quieran ahondar en el tema de la fotografía en España se recomienda leer la Historia de la fotografía en España, de Publio López Mondéjar (1997). También es conveniente leer/ver cinco contribuciones más

${ }^{25}$ Una bibliografía extensa y detallada aparece en el libro de María Jesús Buxó y Jesús M. de Miguel (eds.), De la investigación audiovisual (Barcelona: Proyecto A, 1999).

${ }_{26}$ Museum of Modern Art, en Nueva York. Museo de Arte Contemporáneo, que incluye pintura, escultura, diseño y fotografía. 
en la siguiente secuencia: Josep M. Casademunt (1978), Lee Fontanella (1981), Joan Fontcuberta (1983), Marie-Loup Sougez (1991) y Manuel Santos (1991). Es importante consultar las fotos de la exposición Europalia 1985, en el catálogo titulado Aspecten van Spanje (1985), y las de la exposición Cuatro direcciones (Santos, 1991), referente a las décadas 1970-1990.

Para personas que apenas manejan cámara fotográfica y quieren empezar, les conviene leer The Camera, de Ansel Adams, como iniciación. El manual de técnica fotográfica más básico en castellano es el de Michael Langford, La fotografía paso a paso (1978 publicado en Gran Bretaña, pero en su octava reimpresión en España, 1990), o quizá el de John P. Schaefer, Basic Techniques of Photography (1992). Hay numerosos cursos de iniciación, pero que suelen terminar imponiendo los estándares y cánones de la "fotografía bella», es decir, centrada, iluminada, posada, de naturaleza, pictoralista. Suelen enseñar poco de fotografía social y menos aún de etnografía social.

La revista de fotografía mejor considerada en el mundo es Aperture (Aperture Inc., 20 East 23 Street, New York, NY 10010), existente desde 1952, con cuatro números anuales. Aperture Foundation Inc. es también una editorial -Aperture Monograph- y una librería con un extenso catálogo de libros de fotografía, que edita un catálogo anual (10\% de descuento a los/as suscriptores), y una galería fotográfica: Burden Gallery. El «MoMA», o The Museum of Modern Art (11 West 53 Street, New York, NY 10019) —la institución más importante en la historia de la fotografía-, edita un MoMA Members Quarterly y un Members Calendar mensual donde se incluyen noticias de fotografía. Es posible ser miembro internacional. Existe además una Society for Visual Anthropology (parte de la AAA, American Anthropological Association) en Berkeley, California, que edita la revista Visual Anthropology Review.

Hay pocas librerías especializadas en fotografía en España. En Barcelona se recomienda (por orden de libros que tienen): Tartessos (Canuda 35, 08002 Barcelona, tel. 3018181 ; incluye una sala de exposiciones fotográficas y un interesante taller contracultural); Crisol (Consejo de Ciento 341, casi esquina a Rambla de Cataluña; en el piso de abajo tiene también buen material fotográfico), antes conocido como Tocs; Laie Librería Café (Pau Claris 85, con un restaurante/café agradable y algo snob), y Áncora y Delfín (Avenida Diagonal, 564), más especializada en libros de arte. La mejor colección de libros de fotografía puede verse en la excelente librería Kowasa: Libros de Fotografía, en la calle Mallorca 235, con una galería de fotos en el primer piso ${ }^{27}$. Para los libros oficiales, o del Ministerio de Cultura, en Barcelona se puede visitar la Librería del Ministerio de Cultura que está en Muntaner 221 (casi esquina Diagonal sur). En Madrid es interesante la librería Gaudí (calle Argensola 13, Madrid). El París la librería más recomendable es La Chambre Claire: Librairie Internationale de Photographie (14 rue Saint-Sulpice, 75006 París; facilitan un catálogo trimestral de sus existencias). Existe además el Centre National de la Pho-

27 Su director, Hubert de Wangen, es una excelente fuente de información sobre Fotografía. 
tographie (42 avenue des Gobelins, 75013 París), con la popular colección «Photo Poche» (los libritos negros, de fotógrafos/as célebres). En Londres está The Photographers' Gallery que tiene una librería especializada importante (8 Great New-Port Street, London WC2H 7HY); edita un catálogo anual (astutamente no proporciona información editorial). En Nueva York está el International Center for Photography (1133 Sixth Avenue en la 43rd Street, New York, NY 10036). Tiene una sala de exposiciones, programas educativos y dos tiendas; edita un catálogo de "Books and Gifts». Excelente librería de segunda mano es Strand, que incluye una buena sección de fotografía (está en Broadway con la calle octava). Los libros anglosajones se pueden comprar muy bien a través de Dillons (en Londres) ${ }^{28}$.

Sobre Cataluña se pueden obtener noticias de fotografía a través de Foto Guia, con cinco números anuales (Llibertat 24, bajos derecha, 08012 Barcelona). Existe además una Federación Catalana de Fotografía (Apartado 326, 08240 Manresa). La Agrupació Fotogràfica de Catalunya - fundada en 1923 - tiene una biblioteca (Duque de la Victoria 14, 08002 Barcelona) y edita un boletín informativo bimensual. Existen algunas otras iniciativas, como el Institut d'Estudis Fotogràfics de Catalunya (Comte d'Urgell 187, 08036 Barcelona), o el «espacio fotográfico y crepería» Maple Syrup (Verdaguer i Callís 8, 08003 Barcelona), frente al Palau de la Música (de ocho de la tarde a una de la madrugada).

Para referencias profesionales, el tomo segundo del catálogo de la exposición Cuatro direcciones: Fotografía contemporánea española, 1970-1990, que se titula Libro de referencia (editado por Manuel Santos, 1991, 203 pp.) es útil. Incluye las biografías profesionales de fotógrafos/as españoles, así como las direcciones de: galerías, festivales, colecciones, revistas, críticos, centros de enseñanza, agencias, y asociaciones. También es útil el catálogo de libros y de fotos editados por la Biblioteca Nacional, 150 años de fotografía en la Biblioteca Nacional (publicado en 1989, 375 pp.).

Las lecturas sobre Fotografía puede completarse haciendo fotografías; termina siendo una tentación irrefrenable. El objetivo de los proyectos en ciencias sociales es combinar la imagen fotográfica con el texto escrito, y encontrar sistemas innovadores foto/texto para analizar la realidad social. No es necesario saber manejar bien una cámara fotográfica. Se entiende que la calidad técnica de las fotos no es el objetivo fundamental, sino el marco teórico y la idea sociológica detrás de cada disparo (de la cámara). De entrada se recomienda una cámara manual, con un objetivo de $50 \mathrm{~mm}$, aproximadamente lo que ve el ojo humano (es decir, 45 grados de ángulo de campo). Para foto sociológica puede preferirse a veces un gran angular no exagerado (por ejemplo, de $35 \mathrm{~mm}$, con 64 grados de ángulo de visión). Conviene evitar el teleobjetivo (salvo para retratos) y sobre todo el zoom. Se recomienda empezar con film

${ }^{28}$ Excelente librería y distribuidora: Dillons The Bookstore, 82 Gower Street, London WC1E 6EQ, Gran Bretaña. 
blanco y negro, y luego pasar al color. Hay muchos laboratorios para revelar fotos. En Barcelona, para blanco y negro, uno muy bueno es Còpia: Laboratori Blanc i Negre (en la calle Provença 215, principal, 08008 Barcelona), y en color, Manual Color (calle Rocafort 215, bajos, 08029 Barcelona). Ambos son laboratorios especializados, con una oferta amplia de trabajos y experiencia profesional.

La mayor dificultad en la investigación social está en combinar foto y texto. Un ejemplo excelente a seguir es el de los doce proyectos de Exploring Society Photographically (Howard S. Becker ed., 1981) o los 25 proyectos de Photography/Politics: Two (Patricia Holland et al., 1989). Leer Goffman y Bourdieu es una gran ayuda. Se aprende Fotografía leyendo sobre Fotografía, haciendo fotografías y debatiendo sobre ellas. Actualmente la enseñanza de la Sociología de la Fotografía, en España, sólo se realiza en el Doctorado de Sociología Avanzada de la Universidad de Barcelona (con información al día en docsoc@riscd2.eco.ub.es, o bien en demiguel@eco.ub.es, y en la web: www.ub.es/sociol/sociolog.htm).

La bibliografía instantánea que sigue a continuación es selectiva. Incluye referencias esenciales para aprender sobre las relaciones entre Sociología y Fotografía. El centenar de libros han sido utilizados en clases reales. Suponen algún avance en el peculiar conocimiento de la fotografía sociológica. Aparece por orden alfabético, y hace referencia además a algunos/as autores importantes para los que no hay una bibliografía accesible en nuestro país. Los fotógrafos/as más importantes aparecen con sus fechas de nacimiento y muerte. Está mínimamente comentada para ayudar a la selección inicial. Los libros que consideramos más importantes, o cuya contribución es mayor, llevan un asterisco* delante. Para una bibliografía más extensa de fotografía en las ciencias sociales véase el libro de María Jesús BuXó y Jesús M. DE Miguel, eds., De la investigación audiovisual (Barcelona: Proyecto A, 1998).

*A Day in the Life of Spain (1987): Nueva York: Collins Publishers, 220 pp. Proyecto dirigido por Rick SMOLAN y David CoHEN. Colección de fotografías realizadas por 100 fotógrafos/as (25 españoles/as y 75 extranjeros/as) el día 7 de mayo de 1987. La selección se realizó sobre unas 120.000 fotos. La portada kitch — aunque no lo parece- es de Cristina GARCía Rodero. La versión española se titula Un día en la vida de España (Barcelona: Planeta, 224 pp.), La primera página del título añade: «Fotografiada en un día, 7 de mayo de 1987, por 100 de los mejores reporteros gráficos del mundo». Entre ellos/as está el rey Juan Carlos (se publica una foto en la que aparece su mujer, hijas y perros, p. 125) y el entonces presidente del Gobierno Felipe González (no se publica ninguna foto de las realizadas por él).

Аввотт, Berenice (1988): Berenice Abbott. Nueva York: Aperture Foundation, 93 pp. Es el número nueve de "Aperture Masters of Photography", con un ensayo preliminar de Julia VAN HAAFTEN. Incluye fotografías desde 1927 hasta 1966, y no sólo sus famosas fotos de Nueva York.

*Adams, Ansel (1980): The Camera. Boston: Little, Brown and Co., 203 pp. Es un manual básico, pero realizado por un fotógrafo de estilo, AA (1902-1984). Se maneja la 11.a edición. El libro es el volumen primero de "The New Ansel Adams Photography Series», que está seguido por The Negative (288 pp.), y por The Print (224 pp.). 
Ades, Dawn (1986): Photomontage. Londres: Thames and Hudson, 176 pp. Es una edición revisada y puesta al día respecto de la original de 1976. Es un texto definitivo sobre el análisis de fotomontajes.

*Agee, James, y Evans, Walker (1988): Let Us Now Praise Famous Men: Three Tenant Families. Boston: Houghton Mifflin Co., 62 fotografías de WE (1903-1976) reproducidas de la FSA y 525 páginas de texto por JA (1909-1955). Reproducción de la edición original de 1941. Trabajo de campo realizado durante el verano de 1936 en Alabama, en tres familias de arrendatarios agrícolas (cultivo de algodón). Uno de los experimentos de combinar texto y fotos, en donde «las fotografías no son ilustrativas. Ellas, y el texto, son co-iguales, mutuamente independientes y completamente colaboradoras» (p. xivii). Es un análisis de la pobreza. Hay una edición en español, Elogiemos ahora a hombres famosos (Barcelona: Seix Barral, en su Biblioteca Breve, 1993), 397 pp., incluyendo 61 fotos antes del texto que aparecen no numeradas.

*Álvarez Bravo, Manuel (1987): Manuel Alvarez Bravo. Nueva York: Aperture Masters of Photography, 93 pp. Selección de 44 fotos de MAB (1902-) — seguramente el fotógrafo latinoamericano más influyente- realizada entre 1925 y 1986. El MoMA ha editado una selección más amplia y reciente.

Álvarez Bravo (ed.) (1995): Luz y tiempo: Colección fotográfica formada por Manuel Álvarez Bravo para la Fundación Cultural Televisa A. C. México DF: Fundación Cultural Televisa AC, tres tomos: 273, 274 y 266 pp. Un esfuerzo considerable de seleccionar fotos — por orden alfabético - de los/as autores más importantes de la fotografía mundial.

Alland, Alexander (1993): Jacob A. Riis: Photographer and Citizen. Nueva York: Aperture, 220 pp. Una larga introducción biográfica de JAR (1849-1914), con una selección de fotos de los diversos libros y portafolios. El prefacio es de Ansel Adams.

Allard, William A. (1989): The Photographic Essay. Boston: Little, Brown and Company, 132 pp. El texto corresponde a Erla Zwingle y a Russell Hart, y es editado por American Photographer. Es una visión novedosa sobre la unión de texto y fotos en reportajes sociales. Incluye un porfolio sobre vascos/as, pp. 70-79. Son fotos en color.

*Arbus, Diane (1972): Diane Arbus: An Aperture Monograph. Nueva York: Aperture Inc. Es uno de los libros centrales en el análisis de la fotografía social estadounidense. El tema es la normalidad visible de la «anormalidad" y marginación social. Una parte de las fotos pertenecen a la exposición New Documents, en el MoMA, en 1967, con las fotografías de DA (1923-1971; nacida como Diane Nemerov) de su segunda época. Incluye un texto introductorio con citas de sus clases en 1971 (el mismo año de su suicidio), así como entrevistas y algunos de sus escritos (pp. 1-15).

*Aspecten van Spanje: Imágenes (1985): Hasselt, Bélgica: Cultureel Centrum, 113 pp. Es una selección de las fotografías sobre España expuestas en Europalia 1985, en Bélgica, por el Gobierno español, cubriendo desde 1852 hasta 1985. Es una edición bilingüe en flamenco y castellano. Es seguramente la mejor selección de fotografías sobre España, fundamentalmente en blanco y negro. De los pioneros incluye varias de Charles Clifford y de J. Laurent. Hay cuatro de José Ortiz Echagüe. Una de Santiago Ramón y Cajal. Tres de las más famosas de Henry Cartier-Bresson de la pre-guerra. Hay varias de la guerra civil (aunque no incluye la "Muerte de un soldado republicano», de Robert Capa). Y de la Sevilla de Brassaï, de 1954. Varios de los castillos de Reinharty Wolf (en 1981). También, la histórica foto de Tejero en las Cortes (1981), de Manuel Pérez Barriopedro, y la niña enferma de colza (1983), de Miguel González.

BanKS, Marcus, y Morphy, Howard (eds.) (1997): Rethinking Visual Anthropology. New Haven: Yale University Press, 306 pp. Compilado por dos británicos supone un texto más novedoso que los usuales sobre antropología visual, aunque los ejemplos son clásicos.

*BARThes, Roland (1990): La cámara lúcida: Nota sobre la fotografía. Barcelona: Paidós, 207 pp. Escrito en 1979, la edición original, parisina, de 1980, tiene el título de La chambre claire siguiendo el título del famoso libro de V. Chevalier, de 1834. Está dividido en 48 mini-ensayos. Es su último libro, de lectura obligada. 
*Becker, Howard S. (ed.) (1981): Exploring Society Photographically. Evanston, Illinois: Mary and Leigh Block Gallery, Northwestern University, 96 pp. Una selección de doce proyectos sociológicos y antropológicos sobre el análisis social mediante fotografía. Es un ejemplo excelente para los proyectos individuales del curso.

Becker, Howard S. (1986): Doing Things Together: Selected Papers. Evanston, Illinois: Northwestern University Press, especialmente las pp. 221-317. Incluye cuatro capítulos seminales sobre fotografía desde la perspectiva sociológica que son lectura obligada: «Photography and sociology» (pp. 221-271), originalmente publicado como artículo en 1974; «Do photographs tell the truth?» (pp. 273-292), cuya versión original es de 1978; "Aesthetics and truth" (pp. 293-301), publicado en 1980; e «Inside State Street: Photographs of building interiors by Kathleen Collins» (pp. 303-317), publicado en 1982.

Benjamin, Walter (1992): Illuminations. Londres: Fontana Press, 267 pp. Traducido del alemán. Con una introducción de Hannah Arendt, «Walter Benjamin: 1892-1940». Incluye el famosos ensayo de "The work of art in the age of mechanical reproduction», tan citado como poco leído.

*Berger, John, et al. (1972): Ways of Seeing. Londres: Penguin Books con la BBC (British Broadcasting Corporation), 166 pp. Está basado en una serie para la televisión de la BBC. Contiene siete ensayos, con 164 ilustraciones (sobre todo cuadros, pero también fotos, y collages). Es una excelente introducción al hecho de mirar, con una perspectiva imaginativa, crítica y femista. Al parecer hay una versión en castellano bajo el título de Modos de ver (Barcelona: Gili Gaya, 1974), y otra con el título de Mirar (Pamplona: Hermann Blume, 1985).

Berger, John, y Mohr, Jean (1982): Another Way of Telling. Nueva York: Pantheon Books, 300 pp. Es una visión crítica muy personal del uso de la fotografía. Incluye la historia — sin palabras - de una campesina en 150 fotos. Mohr trabaja para la OMS, la Cruz Roja y la Unesco. Es una mezcla de fotos, historias, confesiones personal, y teoría sobre la fotografía. Existe una versión reciente en español.

Biblioteca Nacional (1989): 150 años de fotografía en la Biblioteca Nacional. Madrid: Ministerio de Cultura y Ediciones El Viso, 375 pp. Se refiere a las colecciones de fotos de la Biblioteca Nacional (en Madrid) desde 1839 hasta 1989, editadas por Gerardo F. Kurtz e Isabel Ortega. Incluye un capítulo sobre la guerra civil (pp. 267 a 293). Cubre también la fotografía de Charles Clifford, J. Laurent y la de José Ortiz Echagüe, como los autores más sociales. También tiene una introducción ensayística de Lee Fontanella, sobre «150 años de fotografía: Contemplación y comprensión» (pp. 16-27).

*Bolton, Richard (ed.) (1989): The Contest of Meaning: Critical Histories of Photography. Cambridge, Massachusetts: The MIT Press, 407 pp. Es un libro esencial. Contiene 14 estudios con análisis críticos de la historia tradicional de la fotografía (fundamentalmente en los Estados Unidos). Hay cuatro capítulos sobre cómo la fotografía contruye las diferencias por género, y tres sobre la forma en que la fotografía es utilizada para promocionar intereses de clase y nacionalistas. Analiza además la ideologización y utilización perversa de la obra de Diane Arbus y de Richard Avedon. Es importante el capítulo de Martha Rosler, sobre «In, around, and afterthoughts (on documentary photography)» (pp. 302-341).

*Bourdieu, Pierre, et al. (1965): Un art moyen: Essai sur les usages sociaux de la photographie. París: Les Éditions de Minuit, 361 pp. Segunda edición en 1989. Escrito con Luc Boltanski, Robert Castel, Jean C. Chamboredon y otros. Uno de los análisis sociológicos básicos de la fotografía. Existe una edición - difícil de conseguir- en castellano: La fotografía, un arte intermedio (México DF: Editorial Nueva Imagen, 1980).

BRANDT, Bill (1983): London in the Thirties. Londres: Gordon Fraser, 96 pp. Una selección de las fotos de los años treinta de BB (1904-1983), algunas publicadas originalmente en 1938, como A Night in London. Sobre las diferencias de clase social en Londres en esos años. Es una fotografía más testimonial que sus desnudos (1945-1980) y sus retratos posteriores. Incluye la famosa «Dancing the Lambeth Walk» (número 15)

Brassaï (1954): Séville en fête. París: Robert Delpire, 153 pp. Por el húngaro Gyula Halász (a) Brassaï (1899-1984). Difícil libro de conseguir, pero excelente. Presenta imágenes estereotipadas, pero interesantes de analizar. Los textos son de Dominique Aubier. 
Burgin, Victor (ed.) (1982): Thinking Photography. Londres: The MacMillan Press, 239. Otra colección de ensayos fotográficos (en este caso ocho) con un enfoque crítico.

*Caldwell, Erskine, y Bourke-White, Margaret (1975): You Have Seen Their Faces. Nueva York: Arno Press en colaboración con Derbibooks Inc., 190 pp. La edición original es de 1937 (Nueva York: The Viking Press). Apareció en Life. Escrito por EC, las fotos son de MBW (1906-1971). Se maneja la reedición de The University of Georgia Press (Athens, Georgia: Brown Thrasher Books, 1995), 54 pp. Se inicia con 17 fotos antes del texto (sin paginar) y luego fotos intercaladas con texto, a un nivel similar de importancia. Es el análisis del pueblo denominado «Middletown» (que es en realidad Muncie, en Indiana), tal y como había sido analizado por los sociólogos Robert y Helen Lynd con el que debe compararse. Es un estudio sobre la pobreza rural.

*CAPA, Robert (1990): Fotografías de Robert Capa sobre la guerra civil española: Colección del Ministerio de Asuntos Exteriores. Madrid: Ediciones El Viso, 137 pp. Contiene 97 fotos de Capa que en 1979 fueron entregadas por Suecia a España, como parte de unos documentos pertenecientes al presidente de la II República, Juan Negrín.

Cartier-Bresson, Henri (1952): Images à la sauvette. París: Éditions Verve. En Estados Unidos, publicado como The Decisive Moment (Nueva York: Simon \& Schuster), 126 fotos de HCB (1908-). Con portada original de Henri Matisse. Colección de fotos sin un orden preciso, pero con una idea general: la de captar el «momento decisivo», único, en que se comunica un mensaje o revelación, normalmente sobre una interrelación humana. La introducción aparece traducida al castellano como "El instante decisivo», pp. 188-201, en Joan Fontcuberta, ed., Estética fotográfica (Barcelona: Blume, 1984).

Casademont, Josep M. (1978): «La fotografía en el Estado español», en Petr Tausk, Historia de la fotografía en el siglo XX. Barcelona: Gustavo Gili. Es lectura obligada. Se refiere a España, no al «Estado español», en los años 1900-1978.

Celant, Germano (ed.) (1994): Mapplethorpe. Barcelona: Electa, 341 pp. Es el extenso catálogo de la exposición en la Fundación Joan Miró, en Barcelona, en 1994. Con una introducción detallada: «El sátiro Mapplethorpe y la ninfa Fotografía» (pp. 11-65).

*Clark, Graham (1997): The Photograph. Oxford: Oxford University Press, 247 pp. Editado en la colección Oxford History of Art. Una excelente introducción temática sobre la Fotografía, según el objeto.

Collier, John, y Collier, Malcolm (1986): Visual Anthropology: Photography As a Research Method. Albuquerque: University of New Mexico Press, 248 pp. Es una segunda versión muy revisada de la publicada en 1967 (por Holt, Rinehart and Winston). Es un buen texto sobre la utilización de la fotografía en la investigación antropológica. Se considera parte del Sterling County Study de Alexander H. Leighton.

Cualladó, Gabriel (1985): Gabriel Cualladó: Fotografías. Madrid: Ministerio de Cultura, 114 pp. Catálogo de la exposición en el Museo Español de Arte Contemporáneo, con fotos de GC (1925-) de 1957 hasta 1985. Incluye diversos proyectos: La Cervecería Alemana (en Madrid), La Real Sociedad Fotográfica, El Rastro, y La Albufera valenciana.

DALí, Salvador (1983): Dalí fotógraf: Dali en els seus fotògrafs. Barcelona: Obra Social de la Caixa de Pensions, 111 pp. De la exposición de 1893 sobre SD (1904-1989). Obras de 17 fotógrafos de Dalí (entre ellos, Brassaï y Man Ray) y algunas fotos del propio Dalí, con una introducción de Luis Revenga. Reproduce el texto de tres artículos de Dalí: «La fotografía pura, creación del espíritu» (de 1927); "El testimonio fotográfico» (1929), y «Psicología no-euclidiana de una fotografía» (1935), sobre las relaciones entre el surrealismo y la fotografía. Con Luis Buñuel realiza El perro andaluz (1929) y La edad de oro (1930).

Davidson, Bruce (1970): East 100th Street: Photographs by Bruce Davidson. Nueva York: Museum of Modern Art. Publicada por Harvard University Press. Son las fotos sobre el Spanish Harlem, por BD (1933-).

Delpire, Robert, y Frizot, Michel (1989): Histoire de voir. París: Centre National de la Photographie, 3 vols., 143 pp. cada uno, en la "Collection Photo Poche». Es una historia de la fotografía a través de una foto por cada fotógrafo/a importante, con un texto de una página 
cada uno/a. Los tres tomos incluyen De l'invention a l'art photographique (1839-1880), Le medium des temps modernes (1880-1939) y De l'instant a l'imaginaire (1930-1970). La selección es adecuada y equilibra bien Estados Unidos y Europa. Ofrece información biográfica útil, pero no sirve realmente como un análisis histórico.

*Dicctionaire de la photo (1996): París: Larousse, 768 pp. Editado por Michel Guillemot. Excelente enciclopedia fotográfica al día, equilibrada con contribuciones europeas.

*Dubois, Philippe (1986): El acto fotográfico: De la representación a la recepción. Barcelona: Paidós, 191 pp. La edición original en francés es de 1983 (Bruselas: Éditions Labor). Es un ensayo sobre las relaciones entre fotografía y realidad.

EdwardS, Elizabeth (ed.) (1992): Antropology and Photography, 1860-1920. New Haven: Yale University Press, en colaboración con The Royal Anthropological Institute de Londres, 275 pp. Además de los aspectos teóricos e históricos, el libro incluye abundantes estudios de casos.

*Evans, Walker (1988): American Photographs. Nueva York: The Museum of Modern Art, 205 pp. Es la edición del cincuenta aniversario del libro, originalmente publicado en 1938, y reeditado en 1962. Contiene un ensayo de Lincoln Kirstein. Son 37 fotografías, la mitad son parte del proyecto de la Farm Security Administration. Representa el primer proyecto general de presentar los Estados Unidos globalmente. El orden de las fotos es importante para su comprensión; y conviene estudiar la separación de las fotos en dos partes diferenciadas. WE (1903-1975) fue catedrático en Yale University desde 1965 a 1975. Es la primera exposición de un solo fotógrafo del MoMA. Se complementa en 1941 con el celebrado libro Let Us Now Praise Famous Men (ver bajo James Agee).

EWING, William A. (1996): El cuerpo: Fotografías de la configuración humana. Madrid: Ediciones Siruela, 432 pp., con 366 fotos (10\% en color). La edición original The Body es de 1994 (Londres: Thames and Hudson). El difícil tema de la fotografía del cuerpo clasificado en una docena de aspectos.

Farràs, Jaume, et al. (1986): La Patum de Berga. Barcelona: Edicions de Nou Art Thor, 64 pp. Fotografías de Climent y Manel Escobet. Análisis socio-antropológico de la fiesta de La Patum y su simbolismo; con fotos y texto.

Fontanella, Lee, y F. KurTz, Gerardo (eds.) (1996): Charles Clifford, fotógrafo de la España de Isabel II. Madrid: Ediciones El Viso y Ministerio de Educación y Cultura, 198 pp. Es el catálogo de la exposición en Madrid, de noviembre 1996 a enero 1997. ChC fue el fotógrafo más importante en España durante los años cincuenta del siglo XIX. De origen galés.

FOnTCubERTA, Joan (1983): "Apéndice sobre la fotografía española», en Beaumont Newhall, Historia de la fotografía desde sus origenes hasta nuestros días. Barcelona: Gustavo Gili. Esta breve historia, por JF (1955-), es lectura obligada.

*Frank, Robert (1986): The Americans. Nueva York: Pantheon Books, 179 pp. Es la famosa colección de fotos realizada por el fotógrafo suizo (1924-) con una beca Guggenheim, en 1955-1956, por todos los Estados Unidos, y que se publicó por vez primera en francés en 1958: Les Américains (París: Robert Delpire). La primera edición anglosajona es de 1959 (Nueva York: Grove Press). Con introducción de Jack Kerouac (el autor de On the Road). Es una visión veinte años después, y mucho más crítica que la de Walker Evans, también en el MoMA (en 1938), con la que tiene que ser comparada. Recibió críticas muy negativas en su exhibición de 1958, pero fue luego un libro muy influyente. La presente edición contiene 83 fotografías. Es importante la simbología de la bandera y los temas de estratificacións social y étnica (entre otros).

FreUnd, Gisèle (1986): La fotografía, como documento social. Barcelona: Gustavo Gili, 207 pp. Cuarta edición (la primera, en castellano, es de 1976) del libro originalmente en francés, publicado en 1974 (París: Éditions du Seuil, 223 pp.), bajo el título menos crítico de Photographie et société. Gisèle es socióloga y fotógrafa, y realiza una historia —algo ensayísticade la historia de la fotografía.

Friedlander, Lee (1992): Lee Friedlander. Valencia: IVAM Centre Julio González, 154 pp. Es el catálogo de una exposición, en el Instituto Valenciano de Arte Moderno (en realidad es arte "contemporáneo»), con una selección de 126 fotos en blanco y negro de LF (1934-). 
*Fundación Gregorio Marañón (ed.) (1993): Viaje a las Hurdes: El manuscrito inédito de Gregorio Marañón y las fotografías de la visita de Alfonso XIII. Madrid: El País Aguilar, 206 pp. Descripción del viaje del Rey, en junio de 1922, a Las Hurdes, con varios artículos analíticos (interesante, el de Luis Carandell) y el cuaderno de notas de Marañón. Incluye las fotos: «Imágenes del histórico viaje» (pp. 101 a 144) en granate.

*Galassi, Peter (ed.) (1991): Pleasures and Terrors of Domestic Comfort. Nueva York: The Museum of Modern Art, 128 pp. Análisis de la vida doméstica en los Estados Unidos, en 125 fotos de una cincuentena de fotógrafos/as contemporáneos. Es el catálogo de la exposición, en el MoMA.

*García Rodero, Cristina (1989): España oculta. Barcelona: Lundwerg. Selección de 126 fotos realizadas entre 1975 y 1989. La presentación es de Julio Caro Baroja. Es una de las contribuciones más importantes en España. Temas de fiestas religiosas y seculares, en una cierta tradición de la España negra. Resalta más el esteticismo que el análisis de la realidad social. La edición francesa, Espagne occulte, es de 1990.

*Goffman, Erving (1979): Gender Advertisements. Nueva York: Harper \& Row, 84 pp. La versión original apareció en Studies in the Anthropology of Visual Communication en 1976. Es un libro básico para la teorización sociológica sobre la discriminación sexual. Análisis de 508 fotografías comerciales (de publicidad) sobre los roles femenino/masculino.

*Goldberg, Vicki (ed.) (1988): Photography in Print: Writings From 1816 to the Present. Albuquerque: University of New Mexico Press, 570 pp. Es una edición nueva sobre la original de 1981. Edición de 75 textos sobre fotografía de diferentes autores. Es una excelente selección, con textos importantes.

Goldsen, Rose K. (1978): The Show and Tell Machine: How Television Works and Works You Over. Nueva York: A Delta Book, 441 pp. Una excelente crítica sociológica sobre la televisión, con un desarrollo teórico sobre sociología de la imagen.

Halle, David (1993): Inside Culture: Art and Class in the American Home. Chicago: The University of Chicago Press, $261 \mathrm{pp}$. Análisis de las pinturas, esculturas y fotos utilizadas en la vida doméstica (el hogar).

*Hine, Lewis W. (1991): Lewis Hine. Gijón, Asturias: Museo Casa Natal de Jovellanos, 123 pp. Catálogo de una exposición por Francia y España, en 1991, con una selección de fotos desde 1905 hasta 1931.

Holland, Patricia; Spence, Jo, y Watney, Simon (1989): Photography/ Politics: Two. Londres: Methuen \& Co., 198 pp. Contiene 25 ensayos críticos sobre la política - y la política sexual- de la fotografía en la actualidad, como estructura de la representación. Se plantea como proyectos alternativos. Es uno de los libros más imaginativos y originales sobre el tema.

Jefrerey, Ian (1981): Photography: A Concise History. Londres: Thames and Hudson, 248 pp. Una historia de la fotografía equilibrada entre Estados Unidos y Europa. Basada en la obra de fotógrafos/as y en corrientes artísticas. Con bastante contenido social.

*Laiglesia, Beatriz DE (ed.) (1989): Efemérides, 1939-1989. Madrid: Agencia EFE, 319 pp. Una revisión fotográfica de medio siglo de historia de España (que coincide con la existencia de EFE), año por año, con una selección de las fotos de prensa más significativas de los diez millones de fotos del archivo. Cada conjunto de fotos anual va precedida de un texto breve autobiográfico de un/a intelectual o político.

Lange, Dorothea (1989): Dorothea Lange. París: Nathan Image, 96 pp. Versión francesa —en la colección Les Maîtres de la Photographie- de una selección de fotos de DL (1895-1965), fundamentalmente sobre la Gran Depresión en los Estados Unidos, para la Farm Security Administration (bajo la dirección de Roy Stryker).

LANGFORD, Michael (1991): La fotografía paso a paso. Barcelona: Hermann Blume, 224 pp. Es la décima impresión de la edición de 1979 del texto británico de 1978. Es un texto de introducción a la técnica fotográfica, didáctico y global. Se recomienda como texto de introducción. 
LAURENT, Juan (1983): J. Laurent. I: La documentación fotográfica de la Dirección General de Bellas Artes y Archivos. Madrid: Ministerio de Cultura, 205 pp. Contiene los fondos del archivo Ruiz Vernacci con las fotografías de JL (1816-1893) realizadas por J. Laurent y Cía. en España entre 1857 y 1893. En su mayoría son fotos de edificios, monumentos y obras públicas, con algunos «tipos españoles» (de una colección de 100 tarjetas), y otras de la Exposición de Filipinas de 1887, en el Palacio de Cristal del Parque del Retiro en Madrid.

*López Mondéjar, Publio (1997): Historia de la fotografía en España. Barcelona: Lunwerg Editores, 303 pp. Cubre el origen y desarrollo de la fotografía desde 1839 hasta los años noventa. Puede considerarse como el manual estándar, aunque con limitaciones de interpretación social.

LyOn, Danny (1993): Danny Lyon: Fotografies, 1959-1990. Barcelona: Fundació La Caixa, 102 pp. Es una exposición organizada por el Center for Creative Photography (CCP, University of Arizona, Tucson) y el Folkwang Museum (Essen, Alemania). Son 172 fotos divididas en once proyectos. Incluye una veintena de fotos de The Bikeriders, 1963-1966, que es uno de sus portafolios más importantes. Incluye un ensayo de Ute Eskildsen, sobre «El compromiso social como aventura personal».

*Llinàs, Pepa, y Ardévol, Elisenda (1989): Imatges de la dona gitana: Camp de la Bota, 19811988. Barcelona: Jonc 74, 86 pp. Combinación acertada de texto y 46 fotos (realizadas por Llinàs, médica y fotógrafa) para analizar la situación de la mujer gitana en Barcelona. La foto «L'orgull de la maternitat», de 1985, es histórica (p. 56). El librito incluye una traducción del texto al castellano, en las pp. 81-86.

*Marsal, Juan F. (1972): Hacer la América: Biografía de un emigrante. Barcelona: Ariel, 340 pp. La historia de vida de un minutero (fotógrafo ambulante) español en Argentina, su vida y penalidades - contra-mito del indiano- admirablemente descritas en su propio texto autobiográfico, recogido por el sociólogo Pancho Marsal. Un clásico del método biográfico en nuestro país.

Mead, Margaret, y Cooke Macgregor, Frances (1951): Growth and Culture: A Photographic Study of Balinese Childhood. Nueva York: G. P. Putnam's Sons. Es una comparación con Estados Unidos del famoso estudio de Gregory Bateson y Margaret Mead, Balinese Character: A Photographic Analysis (Nueva York: Wilbur G. Valentine, Special Publications of the New York Academy of Sciences, 1942), vol 2.

Michals, Duane (1990): Duane Michals. Londres: Thames and Hudson. Publicado originalmente en francés en 1983 (por el Centre National de la Photographie). Ejemplo de fotosecuencias, con textos manuscritos anotados al margen.

Mitchell, William J. (1992): The Reconfigured Eye: Visual Truth in the Post-Photographic Era. Cambridge, Massachusetts: The MIT Press, 273 pp. Excelente discusión sobre la veracidad y el cambio de la fotografía actual.

*Newhall, Beaumont (1988): The History of Photography, 5. ${ }^{a}$ ed. Nueva York: The Museum of Modern Art, 319 pp. Una historia oficial — y escorada hacia Norteamérica - de la Fotografía. La primera edición coincide con el catálogo de la exposición montada por el propio Newhall en el MoMA en 1937, Photography 1839-1937, pero la quinta está revisada y puesta al día hasta 1982. Define el canon de lo que es importante (aunque con ausencias notables). España no aparece. Es una historia cronológica desde 1839, aunque los capítulos se titulan analíticamente. Salvo el capítulo 13 que es sobre "Documentary Photography", su análisis de la condición humana es escaso. Existe una edición en castellano, Historia de la fotografía desde sus origenes hasta nuestros días, publicada por la Editorial Gustavo Gili (Barcelona, 1983), que contiene un apéndice de Joan Fotcuberta, titulado «Notas sobre la fotografía española».

*Nixon, Nicholas (1988): Nicholas Nixon: Pictures of People. Nueva York: The Museum of Modern Art, 123 pp. Catálogo de la exposición realizada en el MoMA en el mismo año. Incluye fotos de NN (1947-) desde 1978 hasta 1982, sobre los temas de porches, viejos/as, infancia. También, la famosa serie de "The Brown Sisters» (anualmente, desde 1975 hasta 1987), y el dramático "People With AIDS», con la historia de un paciente de sida desde agosto 1987 hasta febrero 1988 , en doce fotos. 
Ortiz Echagüe, José (1983): «Medio siglo de actividad fotográfica», PhotoVision 9, pp. 5-6, con fotos en pp. 11-34, y portada. Incluye 27 fotos de JOE, fechadas entre 1909 y 1964 . El artículo es una reproducción del publicado en The American Annual of Photography en 1950.

RaY, Violet (1984): Advertising the Contradictions. Berkeley, California: New College of California Gallery, 32 pp. Fotomontajes contra-anuncios: «los collages no son anuncios, son una sentencia artística acerca de la cultura creada por los anuncios». La crítica ideológica es obvia en cada uno de los fotomontajes.

Renau, Josep (1977): The American Way of Life: Fotomontajes, 1952-1966. Barcelona: Gustavo Gili, 97 pp. Originalmente publicado como Fata Morgana USA (en Berlín), en 1967, incluye diez años de sus fotomontajes, y como Fata Morgana: American Way of Life (en 1989). Realizado por el artista valenciano JR (1907-) exilado en México. Publicado posteriormente como Fata Morgana USA: The American Way of Life por el IVAM Centre Julio González y Fundació Josep Renau (Valencia, 1989), 128 pp.

*RiIs, Jacob A. (1971): How the Other Half Lives: Studies Among the Tenements of New York. Nueva York: Dover, 233 pp. Con un prefacio de Charles A. Madison. Originalmente publicado en 1890 por el police reporter JR (1849-1914; nacido en Dinamarca) contenía sólo 38 fotos del Lower East Side de Nueva York. La versión actual muestra 100 fotos, actualmente en el Museum of the City of New York. La obra, que fue reeditada en 1901 (es la edición que se reproduce aquí), fue luego olvidada hasta 1947. Es una de las obras más importante de la historia de la fotografía social y una de las que mejor combina texto con análisis sociológico y con fotos. Significativamente es una de las más antiguas, lo que sugiere que el progreso realizado en un siglo ha sido escaso. La obra fue continuada en los libros Children of the Poor (1892), Out of Mulberry Street (1898), The Making of an American (1901) y Children of the Tenements (1903). Todos ellos dentro del más puro reformismo social norteamericano. Véase también el libro editado por Alexander Alland (1993).

Rosemblum, Barbara (1978): Photographers at Work: A Sociology of Photographic Styles. Nueva York: Holmes \& Meier Publishers, 144 pp. Análisis de las relaciones entre estructuras sociales y estilos fotográficos, por una profesora de la Universidad de Stanford (Departamento de Sociología).

Rosenblum, Naomi (1989): A World History of Photography. Nueva York: Abbeville Press, 672 pp. Es una edición revisada, con la evolución cronológica desde 1839 hasta los años ochenta. Incluye una selección de 784 fotos.

SAlgado, Sebastião (1988): Sahel: El fin del camino. Madrid: Comunidad de Madrid. Colección de fotos realizadas en 1984-1985 en África por el fotógrafo de Magnum, para (y con) la colaboración de la organización Médicos Sin Fronteras. Temas del hambre, enfermedad y muerte en Mali, Sudán y Etiopía. Brevísimo prólogo de Rosa Montero. Incluye una descripción del contexto de cada fotografía (pp. 125-129). La edición original francesa es de 1986: Sahel, l'homme en dêtresse, coincidiendo con su exposición en París.

*Salgado, Sebastião (1993): Workers: An Archeology of the Industrial Age. Londres: Phaidon Press, 400 pp. Es seguramente la obra más ambiciosa de SS, incluyendo fotos de trabajadores/as industriales en varios países y continentes. Incluye pescadores de Galicia (fotos 79 a 89). Incluye un folleto con la explicación de las fotos.

*Sander, August (1986): Citizens of the Twentieth Century: Portrait Photographs, 1892-1952. Cambridge, Mass.: The MIT Press, 63 pp. de texto y 431 fotos. Editado por su hijo Gunther Sander. Es parte del archivo que quedó del proyecto (nunca terminado) de AS (18761964), reconstruido por Ulrich Keller, quien incluye además un ensayo introductorio amplio (pp. 1-63) de considerable interés. Las 431 fotos se dividen en siete secciones y 45 porfolios. Las secciones son: agricultores, trabajadores, mujeres, ocupaciones, artistas, la gran ciudad, y las últimas personas. Ese es el esquema para el análisis global de la estructura social alemana y de los procesos de cambio social. El último portafolio, «las últimas personas» incluía, originalmente, «idiotas, enfermos, locos y materia», como etapa final de la decadencia de una civilización. Aunque es el portafolio más incompleto y enigmático, es también uno de los más interesante desde un punto de vista sociológico (fotos 421 a 431). 
*SAntos, Manuel (ed.) (1991): Cuatro direcciones: Fotografía contemporánea española, 19701990. Madrid: Lunwerg y Museo Nacional Centro de Arte Reina Sofía, 2 vols. Tomo I: Catálogo de la exposición (265 pp), y Tomo II: Libro de referencia (203 pp.). Es el análisis de las dos décadas de fotografía española dividida en cuatro tendencias: Reflexión y concepto (crítica fría de los absurdos de la vida actual, por ocho fotógrafos); Sueño y sugerencia (estudio del mundo emocional del artista, por 12 fotógrafos, una mujer); Tradición documental (la conciencia documental adormecida durante la dictadura franquista, por 14 fotógrafos, varias mujeres; entre ellos: Gabriel Cualladó, Koldo Chamorro, Alberto García Alix, Cristina García Rodero y Miguel Trillo), y Proceso al medio (elaborada técnica fotográfica con otro tipo de manipulación, y uso de medios, por 17 fotógrafos, tres son mujeres). Es importante la introducción, "Fotografía contemporánea española, 1970-1990», por Manuel Santos (pp. 35-58). El segundo volumen incluye las biografías de los fotógrafos/as participantes en el proyecto, así como una relación de: galerías, festivales, colecciones, revistas, críticos, centros de enseñanza, agencias y asociaciones. Además presenta una cronología de las dos décadas.

Schaefer, John P. (1992): Basic Techniques of Photography. Boston: Little, Brown and Company, 389 pp. Dentro de la colección «An Ansel Adams Guide». Es un manual de fotografía Muchos de los ejemplos son fotos de Ansel Adams. Es un manual útil, que incluye blanco y negro y color.

SChÖTtle, Hugo (1982): Diccionario de la fotografía: Técnica, arte, diseño. Barcelona: Editorial Blume, 357 pp. Edición original alemana (Colonia) en 1978, con el título de Lexikon der Fotografie. Un diccionario práctico y asequible, especialmente para términos técnicos. Incluye un apéndice con las «Figuras destacadas en la historia de la fotografía» (pp. 331-354).

SEROTA, Nicholas (1996): Experience or Interpretation: The Dilemma of Museums of Modern Art. Londres: Thames and Hudson, 63 pp. La concepción del Museo de Arte Contemporáneo como un lugar de encuentro y de experiencias. Presenta los cambios de los museos hacia el siglo XXI.

*SMITH, W. Eugene (1951): «Spanish village: It lives in ancient poverty and faith», Life (9 abril). Colección de 17 fotografías, sobre el pueblo español de Deleitosa (Extremadura), realizadas en 1950. Incluye la foto de los tres guardias civiles, y la de la hilandera. Es un reportaje esencial.

*Smith, W. Eugene (1981): W. Eugene Smith: Master of the Photographic Essay. Nueva York: Aperture, 223 pp. Editado por William S. Johnson. En una edición especial para coleccionistas, con una copia origional de The Spinner, de 1951 (Deleitosa, 1950). Incluye 1.878 fotografías de las 4.000 aproximadamente que se guardan actualmente en el Center for Creative Photography, en la University of Arizona, en Tucson. Sobre el reportaje de "Spanish village» se incluyen 99 fotos (pp. 73-82). Es una fuente importante de información sobre la obra no publicada, o dispersa, de WES.

*SontaG, Susan (1981): Sobre la fotografía. Barcelona: Edhasa, 219 pp. Integración de seis ensayos aparecidos previamente en la revista The New York Review of Books, y posteriormente en 1977, en forma de librito, bajo el título de On Photography. Es un texto básico por sus agudas teorías y capacidad de relacionar ideas. Incluye un análisis de la fotografía norteamericana.

*Spence, Jo (1986): Putting Myself in the Picture: A Political, Personal and Photographic Autobiography. Londres: Camden Press, 221 pp. Basado en una exposición de sus fotos en 1985. Es un análisis foto-autobiográfico imaginativo con 150 fotos. Incluye un análisis crítico del tratamiento de pacientes con cáncer en Gran Bretaña (en el NHS). El punto de vista es feminista y radical.

*STEICHEN, Edward (ed.) (1955): The Family of Man. Nueva York: The Museum of Modern Art, 192 pp. 30th Anniversary Edition de 1986 (2. a edición de 1988), distribuido por Simon \& Schuster. Es, seguramente, el libro más celebrado — y vendido- de la historia de la fotografía. Quizá también uno de los más ideológicos. Catálogo de la histórica exposición del MoMA en 1955, compuesta y escogida por ES (1879-1973, nacido en Luxemburgo). Con- 
tiene 503 fotografías de 68 países, con citas de la Biblia, Shakespeare y proverbios, utilizando la técnica del collage. El tema subyacente es que la condición humana es igual en todas partes, y que la institución familiar es básica e importante. Todo ello demostrado con fotografías y textos (citas o proverbios) ilustrativos.

Stieglitz, Alfred (1989): Alfred Stieglitz. Nueva York: Aperture Foundation, 94 pp. Número 6 de «Aperture Masters of Photography», con un ensayo por Dorothy Norman. Una selección de las fotos del editor de Camera Work. Son desde 1887 hasta 1935. No incluye la famosa foto de la quinta avenida de Nueva York, en el invierno de 1893, pero sí The Steerage, de 1907. Sobre su conceptualización de la «equivalencia», véase mejor el artículo de Minor White, «Equivalencia: Tendencia perpetua», en Joan Fontcuberta, ed., Estética fotográfica (Barcelona: Blume, 1984), pp. 208-218.

SZARKOWSKI, John (1989): Photography Until Now. Nueva York: The Museum of Modern Art, 343 pp. Historia organizada según las pautas de cambio tecnológico, con 178 fotos. Parte de una exposición en el MoMA, en 1989, por el Director del Departamento de Fotografía desde 1962. Es una buena selección de fotos (bien reproducidas) pero con texto engolado.

Trachtenberg, Alan (ed.) (1980): Classic Essays on Photography. New Haven, Connecticut: Leete's Island Books, 300 pp. Notas de Amy Weinstein Meyers. Muy buena colección de ensayos clásicos y contemporáneos, incluye la breve historia de la Fotografía de Walter Benjamin.

Weegee (1982): Weegee's New York: 335 Photographien, 1935-1960. Munich: Schimer/Mosel, 371 pp. Es una selección de fotos de Arthur H. Fellig (a) Weegee (1899-1968) en edición alemana. Incluye fotos de su famoso libro Naked City de 1945.

*Wells, Liz (ed.) (1997): Photography: A Critical Introduction. Londres: Routledge, 307 pp. Manual universitario de teoría fotográfica en un contexto sociopolítico, realizado por profesores británicos.

Weston, Edward (1990): The Daybooks of Edward Weston: I. Mexico. II. California. Nueva York: Aperture, 310 pp. Es la segunda edición, en un solo volumen. Está editado por Nancy Newhall, con un prólogo de Beaumont Newhall. Con 32 fotos en la primera parte y 40 en la segunda. Es un excelente diario editado.

White, Minor (1978): Minor White: Rites and Passages. His Photographs Accompanied by Excepts From His Diaries and Letters. Nueva York, Aperture, 143 pp. Con un ensayo biográfico, por James Baker Hall.

Williams, Val (1991): The Other Observer: Women Photographers in Britain 1900 to the Present, 2. a ed. Londres: Virago Press, 192 pp. La primera edición es de 1986. Análisis de la fotografía femenina —y feminista- británica desde 1840 hasta 1986. No es un mero catálogo de fotos (100 fotos) sino un análisis sociológico e histórico en ocho capítulos. Incluye un estudio del Picture Post. Acompañó la exposición en el National Museum of Photography. Descubre el trabajo de fotógrafas que habían sido olvidadas. Es fascinante comprobar cómo la fotografía de mujeres es distinta a la de los varones.

*Willumson, Glenn G. (1992): W. Eugene Smith and the Photographic Essay. Cambridge: Cambridge University Press, $351 \mathrm{pp}$. Análisis detallado de cuatro de los reportajes principales de WES. Incluye el famoso de «Spanish village: It lives in ancient poverty and faith», publicado en la revista Life, volumen 30, número 15 (9 de abril de 1951, pp. 120-129). La reproducción aparece en las páginas 79-89, y la discusión, en las pp. 90-133. Incluye la reproducción de los contactos en super xx. Se refiere al pueblo de Deleitosa, en Extremadura, en junio de 1950. Es el reportaje más importante sobre España, que merecería un análisis detallado y comparativo.

Winogrand, Garry (1988): Winogrand: Figments from the Real World. Nueva York: The Museum of Modern Art, 260 pp. Es una selección de las fotos de GW (1928-1984) realizada por John Szarkowski, con ocasión de la exposición en el MoMA. Se maneja la segunda edición de 1990. Contiene una introducción sobre el fotógrafo (pp. 11-41). Las inquietantes fotografías se dividen en nueve temas. Es importante «The Street» (pp. 75-97) y "Airport» (pp. 193-219), así como el tema y enfoque general. 
Wood, Nancy C. (1989): Heartland New Mexico: Photographs from the Farm Security Administration, 1935-1943. Albuquerque: University of New Mexico Press, 125 pp. Es una selección de la colección de 270.000 negativos de la Historical Section de la Farm Security Administration (dirigida por Roy E. Stryker) referentes a la depresión en New Mexico. NW (quien había escrito In This Proud Land con Roy Stryker) realiza un análisis de los fotógrafos/as (incluida Dorothea Lange) y los pueblos donde fotografiaron, entrevistando a las personas que recuerdan haber sido fotografiadas cuarenta años antes.

\begin{abstract}
This is the first article in Spain on Visual Sociology. Photography was invented in 1839, the same year in which Auguste Comte began to write about the new science of Sociology. The famous Discours sur l'esprit positif was printed five years later. It is interesting to note that this «discourse» is in fact a long prologue (some 140 pages) to his Philosophical Treaty on Popular Astronmoy. The vision of the world through the telescope or the zoom lens was thus instigated by the new positive spirit of Sociology. Photography and Sociology are twin disciplines, French by birth, and related since their conception. Both were born in Europe, exported to America and reimported back to Europe at the end of the 19th century. Decked out with new trappings and topics, they nonetheless conserved their initial flavour. On this return journey many Europeans lost interest in the social sciences and also in photography. The present fin-de-siècle years have been marked by a renewed interest in photography as an instrument of social analysis. Still photography is a combination of art and technique (mechanical and chemical) which consists of freezing time for an instant. In this sense the analysis of the "crucial moment» can be converted into an excellent instrument for analysing social reality. It is often transformed into a construction of this social reality, different but comparable with the reality engendered by a written text. Ideally, the key aim of Sociology in the 21 st century will be to combine written text and visual image.
\end{abstract}

